\title{
A Parameterization Scheme for Air-Sea Surface Interface Fluxes: Design and Stand-Alone Experiments
}

\author{
HAIXIONG ZHUANG \\ Tianjin Meteorological Service, Tianjin, China \\ XiAOJUN YANG AND ZHENLING WU \\ Tianjin Meteorological Observatory, Tianjin, China
}

(Manuscript received 20 December 2017, in final form 21 March 2018)

\begin{abstract}
Observations show that sea surface temperature (SST) can vary up to several degrees in a day and sea surface energy fluxes up to a few hundreds of watts per square meter. For synoptic- and subsynoptic-scale atmospheric modeling, there remains a need for the parameterization of air-sea surface interaction using simple schemes. In this paper, such a simple scheme, Atmosphere-Ocean Surface Interaction Scheme (AOSIS), is presented so that the short time variations in SST and energy fluxes can be estimated using a small number of atmospheric and oceanic bulk quantities. The scheme consists of three components: a two-layer ocean temperature model, a wind-wave model, and a surface flux model. Numerical experiments show that the scheme performs well in simulating SST and the airsea exchanges. Relative to other schemes, AOSIS shows the following improvements: 1) it simulates SST and the coolskin and warm-layer effect of the ocean mixed layer without the input of ocean bulk temperature of the mixed layer as a prior condition, which is required by most one-layer models; 2) the depth of the ocean mixed layer is allowed to vary according to surface wind stress and buoyancy flux; and 3) a method for computing ocean surface roughness length is proposed, which accounts for the aerodynamic effect of wind-generated waves. For experimental studies, AOSIS can be used in stand-alone mode for the calculation of SST through a small number of bulk measurements. AOSIS can also be used as an interface between the atmosphere and ocean models to be coupled together.
\end{abstract}

\section{Introduction}

It is known that the atmosphere and the ocean form a closely coupled thermodynamic system that essentially governs global climate fluctuations on seasonal to decadal time scales. The El Niño-Southern Oscillation (ENSO) phenomenon is a typical example. Observations also show that sea surface temperatures (SSTs) can vary up to several degrees in a day and the associated variations in surface energy fluxes can be substantial (Fairall et al. 1996a). The atmospheric responses on SST fluctuations on short time scales are less well understood. However, there is reason to believe that they could be significant for synoptic and subsynoptic atmospheric systems. For example, Chan et al. (2001) found that the changes in tropical cyclone intensity are quite sensitive to SST and the response is almost instant. For instances of insignificant weather, such as a clear day, the popular methods used in atmospheric modelling might be sufficient. But for

Corresponding author: Haixiong Zhuang, hxzhuang@sina.com significant weather phenomena, such as a tropical cyclone, the exchange between air and sea is undoubtedly significant. The methods for estimating the exchange fluxes involved are usually more or less problematic. For synopticscale and mesoscale atmospheric modeling, a need remains for the specification and parameterization of the seasurface processes involved.

Correct parameterization of air-sea interaction must be based on a correct understanding of the following components: the energy, momentum, and mass balance at the air-sea interface, particularly the heat budget, which determines the SST and heat fluxes; the wind-wave interaction, which determines the ocean surface roughness length and turbulent fluxes; and the contribution of ocean currents to the heat budget in the ocean mixed layer. In the air-sea interaction modeling, SST is the vital quantity that needs to be considered. And uncertainties in SST represent a major challenge in assessing the heat balance. Observations show that SST can vary up to several degrees in a day and the corresponding sea surface energy fluxes can vary up to a few hundreds of watts per square meter. 
As SST is difficult to measure directly, a model is often required to derive SST from other readily measurable atmospheric and oceanic quantities. For example, Fairall et al. (1996a) estimated SST through the correction of bulk ocean temperature by taking into consideration the coolskin and diurnal warm-layer effects. Zeng et al. (1999) estimated SST from near-surface wind speeds and the diurnal variation of water temperature at $1-\mathrm{m}$ depth. Both these schemes require the bulk temperature of the ocean mixed layer as input. To our best knowledge, in most regional atmospheric prediction models, a daily SST anomaly is not simulated, and daily or weekly average data are often used [e.g., National Centers for Environmental Prediction (NCEP) data]. There remains a need for the parameterization of air-sea exchange processes using simple schemes so that the short time variations in SST and energy fluxes can be estimated using a small number of atmospheric and oceanic bulk quantities.

Several previous modeling studies (e.g., Large et al. 1994; Anderson et al. 1996; Sui et al. 1997; Wu and Moncrieff 2001) have shown that one-dimensional (1D) ocean models can simulate the ocean response to the observed surface forcing and advection during Tropical Ocean and Global Atmosphere Coupled Ocean-Atmosphere Response Experiment (TOGA COARE) program. Large et al. (1994) developed a model with a nonlocal boundary layer "K-profile parameterization," then verified and compared it to alternatives. It included a scheme for determining the boundary layer depth, where the turbulent contribution to the vertical shear of a bulk Richardson number is parameterized. Anderson et al. (1996) found that the observed mixed layer depth in a warm pool is at a depth that allows for maximum warming by capturing a significant portion of the shortwave radiation. Reduced wind forcing yields a shallow mixed layer, which may be associated with cooling of the SST in spite of a net positive heat flux at the sea surface because penetrating shortwave radiation is lost across the base of the shallow, fresh mixed layer. Sui et al. (1997) investigated multiscale air-sea interactions during the TOGA COARE program with an ocean mixed layer model forced by the observed surface heat, water, and momentum fluxes. It was found that the variations of ocean mixed layer are shown to be crucially dependent on the vertical distribution of solar radiation. Wu and Moncrieff (2001) tested the accuracy of a cloud-resolving model (CRM)-derived surface fluxes by using the fluxes to force a 1D model. The 1D model, together with surface forcing from the CRM and the advection of temperature and salinity, simulates the long-term evolution and diurnal variation of the SST.

Since an ocean surface has typically many wave components, which affect its aerodynamic characteristics (Kraus and Businger 1994), the simulation of wind-wave effects is also important for the determination of SST anomalies. Conventionally, this effect is taken into account by using an average roughness length linked to surface stress through the Charnock relationship. Recent studies suggest that the sea surface roughness length also depends on wave age and slope (Oost et al. 2002; Taylor and Yelland 2001). The purpose of this study is to develop an air-sea surface interaction scheme for the computation of SST and surface energy fluxes without the input of ocean bulk temperature observation data, which is required by most one-layer models (e.g., Fairall et al. 1996a,b). Variable ocean mixed layer depth and wind-wave effects will be considered. The performance of the new scheme will be tested against observed data and other schemes.

\section{Scheme description}

The atmosphere and ocean are two thermodynamic systems with exchanges of energy, mass, and momentum at their interface. We refer to the exchange processes as atmosphere-ocean surface interaction. In this study, a new atmosphere-ocean surface interaction scheme (AOSIS) for the simulation of these exchanges and SST is presented. In AOSIS, the ocean surface energy balance equation is solved, and the temperatures of the sea surface, ocean mixed layer, and thermocline are estimated. For the treatment of the aerodynamic transfers in the atmosphere, a new algorithm for computing the ocean surface aerodynamic roughness length is introduced.

The framework of AOSIS is depicted in Fig. 1. It consists of three main components: a two-layer ocean temperature model, a wind-wave model, and a surface flux model. AOSIS is driven by the atmospheric model, which provides air temperature, humidity, wind velocity, radiation, etc., to the ocean-temperature model, the wind-wave model, and the surface-flux model. The windwave model calculates roughness lengths $z_{0 \mathrm{~m}}$ and $z_{0 \mathrm{q}}$ and provides them to the ocean temperature model and the surface flux model. The ocean temperature model simulates SST, using the fluxes estimated from the surface flux model and feeds the signal back to the atmospheric model. At this stage of the study, an ocean model is not coupled with AOSIS but will be considered in the future to provide horizontal heat fluxes to the two-layer ocean temperature model and the ocean current velocity to the wind-wave model.

\section{a. Ocean surface energy balance and heat flux equations}

SST is the important quantity that needs to be considered. For example, uncertainties in SST represent a major challenge in assessing the heat balance. SST is 


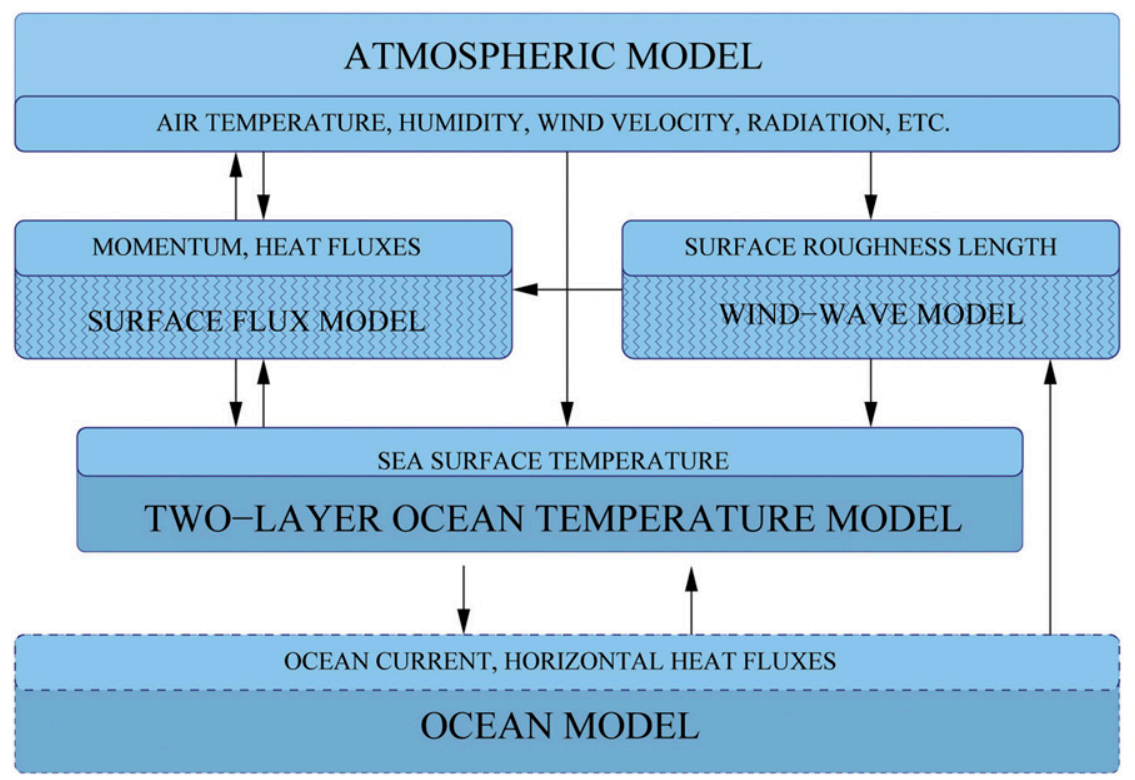

FIG. 1. Framework of AOSIS.

difficult to measure directly. Often, a bulk temperature (i.e., the ocean water temperature averaged over the ocean mixed layer) is measured, and SST is then calculated from the bulk temperature using various schemes. It has been known for some time that SST is often a few tenths of a degree cooler than the bulk temperature. Fairall et al. (1996a) described two simple scaling models (cool skin and warm layer) to estimate these corrections. The SST can also be obtained with small mercury thermometers, thermocouples, or remote infrared thermometers. The positioning errors of placing small mercury thermometers are large in comparison to the thickness of the ocean molecular sublayer, so these have now been replaced by remote infrared thermometers, which measure temperature through the $8-12-\mu \mathrm{m}$ atmospheric radiation window and are representative of a layer of $\sim 100-\mu \mathrm{m}$ thickness. Although remote sensing SST measurements are probably more accurate, they are not always available, and a need for better modeling of SST is still necessary. Since ocean surface currents are wind driven, it is possible to develop a scheme so that the SST can be calculated from available atmospheric and oceanic variables.

We first examine the mechanisms that determine the ocean surface energy balance. The ocean surface energy balance equation can be written as

$$
H_{s}\left(T_{0}\right)+H_{l}\left(T_{0}\right)+R_{n}\left(T_{0}\right)-G_{\mathrm{hw} 0}\left(T_{0}\right)=0,
$$

where $T_{0}$ is SST, $H_{s}$ is sensible heat flux (SHF), $H_{l}$ is latent heat flux (LHF), and $G_{\mathrm{hw} 0}$ is surface heat flux. By definition, all fluxes are positive when pointing upward
(Fig. 2). The $R_{n}$ is net radiation at the ocean surface, which can be calculated by the following equation:

$$
R_{n}=\varepsilon_{w} \sigma T_{0}^{4}+\varepsilon_{w} R_{l},
$$

where $\varepsilon_{w}$ is ocean surface emissivity, $\sigma$ is the StefanBoltzmann constant, and $R_{l}$ is downward longwave radiation [negative in Eq. (2)] from the atmosphere to the ocean surface.

Since a portion of the solar shortwave radiation that reaches the sea surface is reflected back into the space, and the rest passes through the ocean surface and is absorbed by the water in a typical ocean, solar radiation is not included in calculating $R_{n}$. Instead, it is treated as a heat source term $\Delta F_{h}$ in the temperature equation for the ocean mixed layers [Eq. (38)]. The solar shortwave radiation absorbed by the ocean layer with depth $z$ may be approximated by a series of exponentials in the following form:

$$
F_{h}(z)=\left(1-\alpha_{w}\right) R_{s} \sum_{n} a_{n} e^{b_{n} z},
$$

where $z$ is ocean water depth, $\alpha_{w}$ is ocean surface albedo, and $a_{n}$ and $b_{n}$ are coefficients with $a_{n}$ obeying the condition of $\sum a_{n}=1$. Here, the downward solar shortwave radiation $F_{h}$ is negative. Soloviev (1982) suggested representing this sum using three terms with $a_{1}=0.28$, $a_{2}=0.27$, and $a_{3}=0.45$, and $b_{1}=71.5, b_{2}=2.8$, and $b_{3}=0.07 \mathrm{~m}^{-1}$, while Price et al. (1986) used two terms with $a_{1}=0.4$ and $a_{2}=0.6$ and $b_{1}=15.0$ and $b_{2}=$ $0.5 \mathrm{~m}^{-1}$. The Price et al. (1986) absorption profile of shortwave solar radiation is used in AOSIS. 


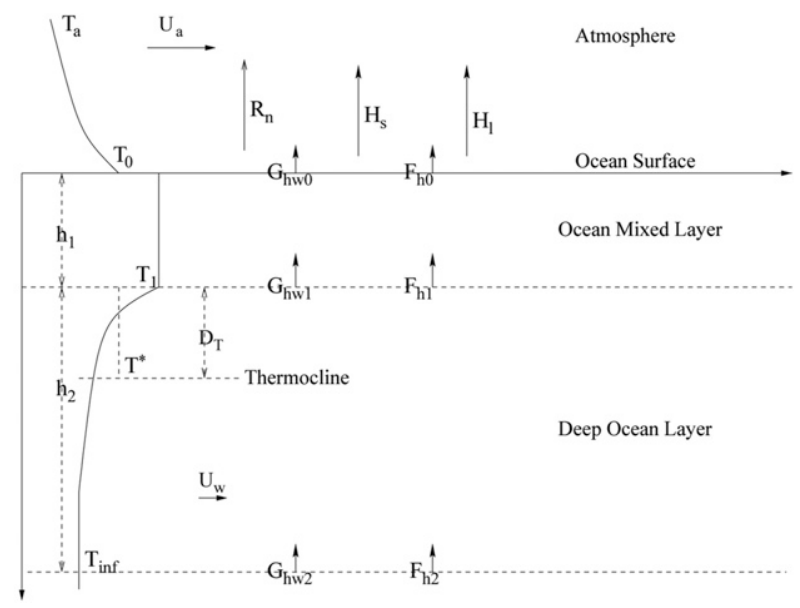

FIG. 2. A schematic illustration of the two-layer ocean temperature model of AOSIS.

The turbulent fluxes of sensible heat $H_{s}$, latent heat $H_{s}$, and momentum $\tau$ can be expressed as

$$
\begin{aligned}
H_{s} & =\rho_{a} c_{\mathrm{pa}} C_{h} S\left(T_{0}-T_{a}\right), \\
H_{l} & =\rho_{a} \lambda C_{e} S\left(q_{s}-q_{a}\right), \\
\tau & =\rho_{a} C_{d} S\left(U_{s}-U_{a}\right),
\end{aligned}
$$

where $\rho_{a}$ is the air density; $c_{\mathrm{pa}}$ is the specific heat capacity of air at constant pressure; $C_{d}, C_{h}$, and $C_{e}$ are the bulk transfer coefficients for momentum, sensible heat, and moisture, respectively; $\lambda$ is latent heat coefficient of vaporization; $T_{a}$ is air temperature at a reference height; $q_{s}$ and $q_{a}$ are the air specific humidities at the ocean surface and the reference height, respectively; $U_{s}$ is the ocean surface current velocity; and $U_{a}$ is the horizontal wind velocity at the reference height. The horizontal energy transport in the mixed layer caused by ocean currents and turbulence is ignored in this study; hence, $U_{s}$ is set to be $0 \mathrm{~m} \mathrm{~s}^{-1}$. To take into account the reduction of vapor pressure caused by a typical salinity of $3.4 \%$, we multiply the saturation specific humidity at a given SST by a factor of 0.98 following Sverdrup et al. (1942) to calculate $q_{s}$ :

$$
q_{s}=0.98 q_{\mathrm{sat}}\left(T_{0}\right) .
$$

The wind speed $S$ at $z_{r}$ with respect to sea surface, as suggested by Schumann (1988) and Godfrey and Beljaars (1991), is composed of the mean wind speed (relative to the ocean surface) $U_{a}-U_{s}$, and a gusty component $w_{g}$, which accounts for subgrid-scale turbulence:

$$
S^{2}=\left(U_{a}-U_{s}\right)^{2}+w_{g}^{2} .
$$

The gusty component $w_{g}$ is proportional to the convective scaling velocity:

$$
w_{g}=\beta W_{*},
$$

where $\beta$ is an empirical constant, depending on the temporal-spatial scale used to compute the averages. The convective scaling velocity $W_{*}$ is given by

$$
W_{*}^{3}=\frac{g}{\rho_{a} T_{a}}\left(\frac{H_{s}}{c_{\mathrm{pa}}}+0.61 T_{a} \frac{H_{l}}{\lambda}\right) z_{i},
$$

with $z_{i}$ being the depth of the convective boundary layer. Fairall et al. (1996b) used $z_{i}=600 \mathrm{~m}$ based on ceilometer and aircraft measurements of the typical boundary layer cloud-base height for the COARE bulk algorithm and $\beta=1.25$ based on the Research Vessel $(\mathrm{R} / \mathrm{V})$ Moana Wave measurements of the horizontal velocity variance [i.e., $\beta^{2}=\left(\sigma_{u}^{2}+\sigma_{v}^{2}\right) / W_{*}^{2}$ ] on the 50-min time scale.

Based on the Monin-Obukhov similarity theory, the transfer coefficients are calculated as

$$
\begin{aligned}
& C_{h}=\frac{\kappa^{2}}{\left[\ln \left(\frac{z_{r}}{z_{0 \mathrm{~h}}}\right)-\Psi_{t}(\zeta)\right]\left[\ln \left(\frac{z_{r}}{z_{0 \mathrm{~m}}}\right)-\Psi_{u}(\zeta)\right]}, \\
& C_{e}=\frac{\kappa^{2}}{\left[\ln \left(\frac{z_{r}}{z_{0 \mathrm{q}}}\right)-\Psi_{q}(\zeta)\right]\left[\ln \left(\frac{z_{r}}{z_{0 \mathrm{~m}}}\right)-\Psi_{u}(\zeta)\right]}, \\
& C_{d}=\frac{\kappa^{2}}{\left[\ln \left(\frac{z_{r}}{z_{0 \mathrm{~m}}}\right)-\Psi_{u}(\zeta)\right]^{2}}
\end{aligned}
$$

Here, $\kappa$ is the von Kármán constant $(=0.4) ; \Psi_{t}, \Psi_{q}$, and $\Psi_{u}$ are the Monin-Obukhov similarity functions for temperature, humidity, and wind profiles $\left(\Psi_{t}=\Psi_{q}\right.$ is assumed); and $\zeta$ is the stability parameter, defined by

$$
\begin{aligned}
\zeta & =\frac{z_{r}}{L}, \\
L^{-1} & =-\frac{k g}{\rho_{a} T_{a} u_{*_{a}}^{3}}\left(\frac{H_{s}}{c_{\mathrm{pa}}}+0.61 T_{a} \frac{H_{l}}{\lambda}\right),
\end{aligned}
$$

where $L$ is the Monin-Obukhov length and $u *_{a}$ is air friction velocity defined as

$$
u_{*_{a}}=\left(\frac{\tau}{\rho_{a}}\right)^{1 / 2} .
$$

\section{b. Two-layer ocean temperature model}

Observations show that ocean temperature and salinity are usually well mixed in a shallow layer below the sea surface, known as the mixed layer (Kraus 
and Businger 1994). This layer has a near-neutral stratification. Ocean mixed layers tend to be bounded below by stratified pycnoclines. Conceptually, we can divide the ocean into several layers, in each of which the vertical gradients of conservative properties are negligibly small. In AOSIS, we divide the ocean into two layers for simplicity: a mixed layer with distinct diurnal variations and a deep ocean layer. The schematic of the two-layer ocean temperature model of AOSIS is illustrated in Fig. 2.

To keep AOSIS simple, the ocean water density $\rho_{w}$ is set to be constant. The time step $\Delta t$ for numerical integration is chosen to be sufficiently small such that, during the interval, the rates of the energy inputs into the ocean can be considered to be constant. The freshwater input is not considered.

In the scheme, SST is by definition given by $T(z=0)$. In the ocean mixed layer, $T(z)$ is assumed to be uniform and defined as $T_{1}$. In the deep ocean layer, $T(z)$ is assumed to decrease exponentially with depth $z$. In summary, the ocean temperature is assumed to have the following profiles:

$$
\begin{gathered}
T(z)=T_{0}, \quad z=0, \\
T(z)=T_{1}, \quad 0<z \leq h_{1}, \\
T(z)=T_{\infty}+\left(T_{1}-T_{\infty}\right) e^{-\left(z-h_{1}\right) / D_{T}}, \\
\quad h_{1}<z<\left(h_{1}+h_{2}\right), \\
T(z)=T_{\infty}, \quad\left(h_{1}+h_{2}\right) \leq z,
\end{gathered}
$$

where $h_{1}$ is the depth of the ocean mixed layer and $h_{2}$ is the depth of the deep ocean layer, which is set at $1000 \mathrm{~m}$, much larger than $h_{1}$. The temperature of the very deep ocean $T_{\infty}$ is a constant of approximately $276 \mathrm{~K} ; D_{T}$ is the $e$-folding depth of the thermocline.

The temperature change with time can be expressed as

$$
c_{\mathrm{pw}} \frac{\partial T}{\partial t}=-\frac{1}{\rho_{w}}\left[\frac{G_{\mathrm{hx}}}{\partial x}+\frac{G_{\mathrm{hy}}}{\partial y}+\frac{\partial\left(G_{\mathrm{hw}}+F_{h}\right)}{\partial z}\right],
$$

where $G_{\mathrm{hx}}$ and $G_{\mathrm{hy}}$ are the horizontal heat fluxes in the $x$ and $y$ dimensions, respectively, and $G_{\mathrm{hw}}$ is the vertical heat flux. For subseasonal time scales, the vertical component of energy divergence is much larger than the horizontal ones. In AOSIS, we have neglected the latter terms; hence, Eq. (21) becomes

$$
c_{\mathrm{pw}} \frac{\partial T}{\partial t}=-\frac{1}{\rho_{w}} \frac{\partial\left(G_{\mathrm{hw}}+F_{h}\right)}{\partial z} .
$$

The vertical heat flux in the ocean $G_{\mathrm{hw}}$ can in general be expressed as

$$
G_{\mathrm{hw}}=\rho_{w} c_{\mathrm{pw}}\left(\overline{T^{\prime} w^{\prime}}-\kappa_{m} \frac{\partial T}{\partial z}\right),
$$

where $T^{\prime}$ and $w^{\prime}$ are the fluctuating components of $T$ and vertical current speed, respectively; and $\kappa_{m}$ is molecular thermal diffusivity. By introducing an eddy diffusivity $K_{\mathrm{hw}}, \overline{T^{\prime} w^{\prime}}$ can be expressed as

$$
\overline{T^{\prime} w^{\prime}}=-K_{\mathrm{hw}} \frac{\partial T}{\partial z} .
$$

Substituting Eq. (24) into Eq. (23) gives

$$
G_{\mathrm{hw}}=-\rho_{w} c_{\mathrm{pw}}\left(K_{\mathrm{hw}}+\kappa_{m}\right) \frac{\partial T}{\partial z} .
$$

The $K_{\mathrm{hw}}$ has the same dimension as $\kappa_{m}$ but is generally much larger than the latter. Further, $K_{\mathrm{hw}}$ is not an intrinsic property of water but a property of turbulence. Unlike $\kappa_{m}, K_{\mathrm{hw}}$ varies with location, sea state, and ocean stratification. In AOSIS, $K_{\mathrm{hw}}$ is expressed as

$$
K_{\mathrm{hw}}=A u_{*_{w}} h^{*},
$$

where $A=0.22 ; h^{*}$ is the average depth of the mixed layer and is set at $10 \mathrm{~m}$; and $u_{*_{w}}$ is the ocean water friction velocity given by

$$
u_{*_{w}} \approx 0.035 u_{*_{a}},
$$

with $u_{a}$ being the air friction velocity.

The molecular diffusivity $\kappa_{m}$ is a function of seawater temperature and salinity. For simplification, $\kappa_{m}$ is set independent of salinity and is calculated as

$$
\kappa_{m}=5 \times 10^{-10}(T-273.16)+1.39 \times 10^{-7} .
$$

While turbulent diffusion dominates in the mixed layer, molecular diffusion dominates in the deep ocean. Heat flux $G_{\mathrm{hw}}$ is thus

$$
G_{\mathrm{hw}}=-\rho_{w} c_{\mathrm{pw}} \kappa_{m} \frac{\partial T}{\partial z} .
$$

On a clear day, the sun deposits an average of about $500 \mathrm{~W} \mathrm{~m}^{-2}$ of heat into the ocean over, say, 12 daylight hours. Half of this heat is absorbed in the upper 2-m layer of water. Such warming leads to a stably stratified surface layer. The depth to which a layer of water can be thoroughly stirred depends on the amount of kinetic energy that is available for this purpose. Thus, the depth of the mixed layer $h_{1}$ is smaller in light-wind conditions, and the temperature increase across the mixed layer is greater. According to Kraus and Businger (1994), $h_{1}$ is given by 


$$
h_{1}=\frac{2 m_{1} u_{* a}^{3}}{B},
$$

where $m_{1}$ is a constant and $B$ is the buoyancy flux at the water side of the air-sea interface. It can be represented by

$$
B=\frac{g}{\rho_{w}}\left[\frac{\alpha_{B}}{c_{\mathrm{pw}}} Q_{w}+\beta_{B} s(E-\mathrm{Pr})\right],
$$

where $Q_{w}=G_{\mathrm{hw} 0}+F_{\mathrm{h} 0}$ is the total surface heat flux into the mixed layer, $E-\operatorname{Pr}$ is the difference between evaporation and precipitation (i.e., net freshwater flux), $s$ is the seawater salinity (set to be $3.5 \%$ in AOSIS), $\alpha_{B}$ is the coefficient of thermal expansion, and $\beta_{B}$ is the coefficient of saline contraction. They are calculated using the following equations (Kraus and Businger 1994):

$$
\begin{aligned}
& \alpha_{B}=8.7(T-273.16)+77.5, \\
& \beta_{B}=779.1-1.66(T-273.16) .
\end{aligned}
$$

According to Eqs. (25) and (29), we have

$$
\begin{aligned}
G_{\mathrm{hw} 0} & =-\rho_{w} c_{\mathrm{pw}}\left(K_{\mathrm{hw}}+\kappa_{m}\right) \frac{T_{0}-T_{1}}{h_{1}}, \\
G_{\mathrm{hw} 1} & =-\rho_{w} c_{\mathrm{pw}} \kappa_{m} \frac{T_{1}-T^{*}}{D_{T}}, \\
G_{\mathrm{hw} 2} & =0,
\end{aligned}
$$

where

$$
T^{*}=\frac{1}{D_{T}} \int_{h_{1}}^{h_{1}+D_{T}} T(z) d z, \quad h_{1}<z<\left(h_{1}+h_{2}\right) .
$$

We can close the energy balance equation [Eq. (1)] with $G_{\mathrm{hw} 0}$ now given. By substituting Eqs. (34) and (35) into Eq. (22), we obtain

$$
\begin{aligned}
\frac{\partial T_{1}}{\partial t}= & -\frac{1}{\rho_{w} c_{\mathrm{pw}}} \frac{G_{\mathrm{hw} 0}-G_{\mathrm{hw} 1}}{h_{1}}-\frac{1}{\rho_{w} c_{\mathrm{pw}}} \frac{\Delta F_{h}}{h_{1}} \\
= & \frac{K_{\mathrm{hw}}+\kappa_{m}}{h_{1}^{2}} T_{0}-\left(\frac{K_{\mathrm{hw}}+\kappa_{m}}{h_{1}^{2}}+\frac{\kappa_{m}}{h_{1} D_{T}}\right) T_{1} \\
& +\frac{\kappa_{m}}{h_{1} D_{T}} T^{*}-\frac{F_{\mathrm{h} 0}-F_{\mathrm{h} 1}}{\rho_{w} c_{\mathrm{pw}} h_{1}}
\end{aligned}
$$

The $e$-folding depth of the thermocline $D_{T}$ varies with time and is dependent on the intensity of turbulence in the mixed layer. Turbulence becomes weaker with increasing depth and is supposed to disappear at $D_{T}$. Deeper $D_{T}$ means more heat is transported into deeper ocean, hence a cooler SST. Note that the temporal variation of $D_{T}$ is determined by

$$
\frac{\partial D_{T}}{\partial t}=\frac{D_{T}}{T_{\infty}-T_{1}} \frac{\partial T_{1}}{\partial t}-\frac{\kappa_{m}}{D_{T}}\left(\frac{T *-T_{1}}{T_{\infty}-T_{1}}-1\right) .
$$

Equations (37), (39), and (40) constitute the two-layer ocean temperature model.

\section{c. Stability profile functions}

According to the Monin-Obukhov similarity theory, the $\Psi_{i}(\zeta)$ function in Eqs. (11), (12), and (13) obeys

$$
\Psi_{i}(\zeta)=\int_{0}^{\zeta} \frac{1-\varphi_{i}(\zeta)}{\zeta} d \zeta, \quad i=u, t
$$

where $\zeta=z / L$ is the stability parameter and $L$ is defined in Eq. (14); the subscript $i=u$ denotes the velocity profile, and $i=t$ denotes the temperature profile. In the limit of free convection, the $\varphi$ functions are

$$
\varphi_{i}(\zeta)=A_{i}(-\zeta)^{-1 / 3}
$$

Grachev et al. (2000) suggested $A_{u}=10$ for velocity and $A_{t}=34$ for temperature and humidity.

However, observations under strong convective conditions do not fully agree with these formulas. According to Businger (1966) and Dyer (1974), $\varphi_{u}$ and $\varphi_{t}$ can be expressed as

$$
\begin{aligned}
& \varphi_{u}(\zeta)=\left(1-\gamma_{u} \zeta\right)^{-1 / 4}, \\
& \varphi_{t}(\zeta)=\left(1-\gamma_{t} \zeta\right)^{-1 / 2},
\end{aligned}
$$

where $\gamma_{u}$ and $\gamma_{t}$ are constants and commonly set to be 16 .

An integration of Eq. (41) subject to Eq. (42) gives

$$
\psi_{i}(\zeta) \equiv \psi_{i, \text { con }}=\frac{3}{2} \ln \left(\frac{y^{3}+y+1}{3}\right)-\sqrt{3} \ln \left(\frac{2 y+1}{\sqrt{3}}\right)+\frac{\pi}{\sqrt{3}},
$$

where $y=\left(1-A_{i} \zeta\right)^{1 / 3}$. An integration of Eq. (41) subject to Eqs. (43) and (44) gives

$$
\begin{gathered}
\psi_{i}(\zeta) \equiv \psi_{u, \text { con }}=2 \ln \left(\frac{1+x}{2}\right)+\ln \left(\frac{1+x^{2}}{2}\right) \\
-2 \tan ^{-1} x+\frac{\pi}{2} \\
\psi_{t}(\zeta) \equiv \psi_{t, \text { con }}=2 \ln \left[\frac{1}{2}\left(1+\sqrt{1-\gamma_{t} \zeta}\right)\right],
\end{gathered}
$$

where $x=\left(1-\gamma_{u} \zeta\right)^{1 / 4}$. 
For practical purposes, it is useful to have a function that interpolates between neutral and free convective conditions. Although Eq. (45) has the theoretically correct freeconvection limit, Eqs. (43), (44), (46), and (47) better describe experimental data for near-neutral conditions. For this reason, we adapt the following interpolation in AOSIS:

$$
\psi_{i}(\zeta)=\frac{\psi_{i, \mathrm{con}}+\zeta^{2} \psi_{i, \mathrm{con}}}{1+\zeta^{2}}, \quad i=u, t
$$

as suggested by Fairall et al. (1996b). This approach gives good agreement with the Businger-Dyer formulation for near-neutral stratifications and, at the same time, satisfies the free-convection limit as $\zeta \rightarrow-\infty$. Further, for stable conditions, we have

$$
\psi_{i}(\zeta)=-\beta_{i} \zeta, \quad i=u, t
$$

with $\beta_{i} \approx 5$.

\section{d. Wind-wave model}

As Eqs. (11), (12), and (13) reveal, the velocity roughness length $z_{0 \mathrm{~m}}$ and the scalar roughness lengths, $z_{q}$ and $z_{h}$, are important parameters for the atmosphereocean surface exchange process. In contrast to a land surface, an ocean surface is full of waves that have spatial and temporal variations. Wind-generated waves determine the small-scale configuration of the air-sea interface, which affects the turbulent transfer. To determine the roughness lengths, it is necessary to understand ocean-wave dynamics.

Since the nineteenth century, scientists have carried out research in the area of wind-wave effects. Subjects of special relevance include the generation, propagation, nonlinear properties, dissipation, and statistical representation of waves. Among these subjects, the generation of waves by wind is the most intriguing problem. Despite the development of Jeffreys's (1925, 1926) sheltering hypothesis, Phillips's (1957) resonance hypothesis, Miles's (1957) quasi-laminar approach, and Janssen's (1982) quasi-linear theory, the understanding of wind-wave generation remains unsatisfactory. The effects of turbulence and wind-wave interaction still require intensive research.

In response to wind and pressure changes at the sea surface, the ocean reacts with waves that occupy different temporal and spatial scales: from capillary waves, which undulate within a fraction of a second over distances smaller than $1 \mathrm{~cm}$, to planetary waves with periods measured in years and wavelengths of thousands of kilometers (Kraus and Businger 1994).

Waves are distinguished from turbulence by the dominance of a conservative restoring force, which increases with increasing departure from equilibrium. In surface waves, this force is due to gravity and to surface tension. In other types of fluid waves, pressure, inertial, or Coriolis forces can play an analogous role.

The sources and sinks of surface wave energy involve three different processes: 1) transfer of energy between different wave modes, 2) dissipation of wave energy, and 3) energy input by the wind.

Any deformation of the sea surface must result in spreading surface waves. Deformations can be caused directly by local air pressure fluctuations or indirectly by horizontal changes in the local wind stress. The initial amplitude of the resulting sea surface perturbation is likely to be small, but it can be amplified if the atmospheric disturbance continues to act over a period of time. This happens if the atmospheric disturbance contains components that match the length scale and propagation speed of free waves at the ocean surface.

\section{e. Wave-induced stress}

The governing equations for the $x$ and $y$ components of the mean wind speed $\bar{u}$ and $\bar{v}$ are

$$
\begin{aligned}
& \frac{D \bar{u}}{D t}-f \bar{v}=-\frac{1}{\rho} \frac{\partial p}{\partial x}+\frac{\partial \tau_{x}}{\partial z}, \\
& \frac{D \bar{v}}{D t}+f \bar{u}=-\frac{1}{\rho} \frac{\partial p}{\partial y}+\frac{\partial \tau_{y}}{\partial z},
\end{aligned}
$$

where $D / D t$ is the total derivative, $f$ is the Coriolis parameter, and $\tau_{x}$ and $\tau_{y}$ are the $x$ and $y$ components of the vertical turbulent momentum fluxes. These equations describe the balances between the rate of momentum change, the effect of Earth's rotation, the pressure gradient force, and the divergence of the vertical momentum fluxes. In the atmospheric surface layer, the turbulent momentum flux terms dominate, and Eqs. (50) and (51) reduce to

$$
\frac{\partial \tau}{\partial z}=\frac{\partial \sqrt{\tau_{x}^{2}+\tau_{y}^{2}}}{\partial z}=0 .
$$

The total momentum flux $\tau$ can be partitioned into

$$
\tau=\tau_{t}+\tau_{w},
$$

where $\tau_{t}$ is turbulent shear stress and $\tau_{w}$ is wave-induced stress. The turbulent shear stress can be calculated by means of a mixed-length model:

$$
\tau_{t}=\rho_{a} l^{2}\left|\frac{\partial U_{0}}{\partial z}\right| \frac{\partial U_{0}}{\partial z},
$$

with the mixing length given by $l=k z$, and $U_{0}=$ $\left(\bar{u}^{2}+\bar{v}^{2}\right)^{1 / 2}$ is the mean wind speed. 
The wind profile is affected by surface waves; this in turn affects wave growth. Thus, the wind profile over a rough sea may differ from that over a smooth surface. For a rough sea, the stages of wave development can be measured by the wave age, $c_{p} / u_{* a}$, where $c_{p}$ is the phase speed of waves with wavelength at the peak of wave spectrum and $u_{* a}$ the friction velocity. Typically, a "young" windy sea has a wave age around 5-10, while an "old" windy sea has a wave age around 25 (Komen et al. 1996). The surface of a young windy sea is rougher than that of an old windy sea.

Airflow over a windy sea slows down by transferring momentum to waves. Snyder et al. (1981) found that the momentum transfer from wind to waves is considerable so that the related wave-induced stress may be a substantial fraction of the total stress in the surface layer. To estimate the effect of waves on the wind, Komen et al. (1996) determined wave-induced stress using a simple wave-growth model and compared the result with the total stress in the surface layer. By analyzing the momentum balance and the rate of change of wind-induced stress, they suggested

$$
\frac{\tau_{w}}{\tau}=\mu \alpha_{p}\left[28\left(\frac{c_{p}}{u_{*_{a}}}\right)-\frac{1}{2}\left(\frac{c_{p}}{u_{*_{a}}}\right)^{2}\right],
$$

where $\alpha_{p}$ is the Philips constant. Based on the data obtained in the Bight of Abaco, Snyder et al. (1981) found $\mu$ to be around 0.25 on average. This result holds for windy seas with $c_{p} / u_{* a}<28$. Note that

$$
\tau=\rho_{a} u_{*_{a}}^{2} .
$$

The estimate of $\tau_{w}$ depends largely on the wave-age dependence on $\alpha_{p}$. Janssen et al. (1984) suggested that

$$
\alpha_{p}=0.57\left(c_{p} / u_{*_{a}}\right)^{-3 / 2} .
$$

Recall that, $c_{p}=\omega_{p} / k_{p}$, where $\omega_{p}=2 \pi / T_{p}$ is the peak angular frequency, $k_{p}=\omega_{p}^{2} / g$ is the corresponding peak wavenumber, and $g$ is the acceleration due to gravity. In AOSIS, $\tau$ and $\tau_{w}$ are calculated using Eqs. (56) and (55).

\section{f. Roughness length}

The velocity roughness length $z_{0 \mathrm{~m}}$ is related to the physical roughness of the surface, but determining the scalar roughness lengths is more complicated (Fairall et al. 1996b). Nikuradse (1933, p. 1) examined pipe flows and suggested characterizing the flows using the roughness Reynolds number:

$$
R_{r}=\frac{u_{* a} z_{0 \mathrm{~m}}}{\nu_{a}}
$$

where $\nu_{a}\left(\cong 1.5 \times 10^{-5} \mathrm{~m}^{2} \mathrm{~s}^{-1}\right)$ is the kinematic viscosity of air. According to Nikuradse (1933, p. 1), the flow is smooth for $R_{r}<0.13$ and rough for $R_{r}>2.5$. It was found that as wind speed decreases, $R_{r}$ approaches a constant value of about 0.11 , and the relationship between roughness length and stress is fixed:

$$
z_{0 \mathrm{~m}}(\text { smooth })=\frac{0.11 \nu_{a}}{u_{*_{a}}}
$$

The ocean surface is fully rough when wind speed exceeds $8 \mathrm{~m} \mathrm{~s}^{-1}$. Charnock (1955) proposed a relationship between roughness length and stress for a rough ocean surface:

$$
z_{0 \mathrm{~m}}(\text { rough })=\alpha_{\mathrm{Ch}} \frac{u_{*_{a}}^{2}}{g},
$$

where $\alpha_{\mathrm{Ch}}$ is a constant of proportionality, known as the Charnock number. Experimental work suggests $0.011<$ $\alpha_{\mathrm{Ch}}<0.018$ (e.g., Wu 1980; Garratt 1977). This formula does not account for wave conditions. Recent research suggests that $z_{0 \mathrm{~m}}$ should be dependent on wave age or wave slope (e.g., Smith et al. 1992; Johnson et al. 1998). Smith et al. (1992) proposed

$$
\alpha_{\mathrm{Ch}}=a\left(c_{p} / u_{*_{a}}\right)^{b},
$$

with $a=0.48$ and $b=1.0$. Based on data obtained in several campaigns at the Dutch research platform in the North Sea, Oost et al. (2002) suggested $a=50, b=-2.5$, and

$$
z_{0 \mathrm{~m}}(\text { rough })=\frac{50}{2 \pi} L_{p}\left(\frac{c_{p}}{u_{*_{a}}}\right)^{-4.5} .
$$

Some researchers believe that $z_{0 \mathrm{~m}}$ is a function of wave slope $\left(Z_{\mathrm{sw}} / L_{p}\right)$, where $Z_{\mathrm{sw}}$ is the significant wave height (commonly used as a measure for average wave height) and $L_{p}$ the peak wavelength of the wave spectrum (Hsu 1974; Taylor and Yelland 2001). However, a clear wave-age dependence has proven hard to detect in open-ocean data (Yelland et al. 1998). The field data generally suggest that seas with a younger wave age have larger $z_{0 \mathrm{~m}}$ than mature seas. Laboratory data from windwave flumes suggest that very young waves are much smoother than expected from the results of field measurements (e.g., Donelan et al. 1993).

To resolve these problems, Taylor and Yelland (2001) proposed that $z_{0 \mathrm{~m}}$ can be predicted from the height and steepness of the waves:

$$
z_{0 \mathrm{~m}}(\text { rough })=A Z_{\mathrm{sw}}\left(\frac{z_{\mathrm{sw}}}{L_{p}}\right)^{B},
$$

and 


$$
L_{p}=\frac{g T_{p}^{2}}{2 \pi} .
$$

The best estimates for the coefficients are $A=1200$ and $B=4.5$. For deep water and fully developed seas, Taylor and Yelland (2001) assumed

$$
\begin{gathered}
Z_{\mathrm{sw}}=A_{\mathrm{zs}} U_{10 \mathrm{n}}^{2}, \\
T_{p}=A_{\mathrm{Tp}} U_{10 \mathrm{n}},
\end{gathered}
$$

where $U_{10 \mathrm{n}}$ is wind speed adjusted to the 10 -m reference level assuming neutral stability and $A_{\mathrm{zs}}$ and $A_{\mathrm{Tp}}$ are constants and set to be 0.0248 and $0.729 \mathrm{~m}^{-1} \mathrm{~s}^{2}$, respectively. Numerical experiments of AOSIS for the Moana Wave data (section 3) show that $A_{\mathrm{Tp}}=0.729$ is probably too large, so it is set at 0.55 .

Drennan et al. (2003) pointed out that if the ocean surface roughness length $z_{0 \mathrm{~m}}$ is dependent on wave age $c_{p} / u_{* a}$ [Eqs. (60) and (61)], then this has the disadvantage that both the dimensionless roughness and the wave age depend strongly on the friction velocity. Consequently, a "significant" correlation between $\alpha_{\mathrm{Ch}}$ and $c_{p} / u_{* a}$ may in fact be spurious, arising from the fact that both variables are themselves highly correlated to $u_{* a}$. Drennan et al. prefer the scaling of roughness to wave height.

Apart from the parameterizations mentioned above, Janssen (1991) assumed that the velocity profile is modified by the presence of waves so that the wind speed $U$ at height $z$ can be written as

$$
U(z)=\frac{u_{* a}}{k} \ln \left(\frac{z+z_{e}-z_{0 \mathrm{~m}}}{z_{e}}\right) .
$$

It can be shown that, if this velocity profile holds, the effective roughness length $z_{e}$ is given by

$$
z_{e}=\frac{z_{0 \mathrm{~m}}}{\sqrt{1-\tau_{w} \tau^{-1}}} .
$$

In fact, Taylor and Yelland's (2001) Eq. (63) is similar to Charnock (1955)'s Eq. (60). Substituting Eqs. (65) and (66) into Eqs. (63) and (64), we find

$$
z_{0 \mathrm{~m}}(\text { rough })=4.0425 \times 10^{-5} \frac{U_{10 \mathrm{n}}^{2}}{g} .
$$

Equations (60), (68), and (69) lead to the following formula:

$$
z_{0 \mathrm{~m}}(\text { rough })=\frac{A_{z 0}}{\sqrt{1-\tau_{w} \tau^{-1}}} \frac{u_{*_{a}}^{2}}{g},
$$

where $A_{\mathrm{z} 0}$ is a coefficient depending on
- stability, $z / L$ or $h / L$, where $h$ is the height of the boundary layer;

- gustiness, $\sigma_{u} / U$, where $\sigma_{u}$ is the square root of wind speed variance;

- fetch $F$ the distance to the shore; and

- swell, which represents the angles $\alpha_{n}$ between the wind and various waves.

The $A_{\mathrm{z} 0}$ may be expressed formally as

$$
A_{\mathrm{z} 0}=A_{\mathrm{z} 0 \mathrm{n}} f\left(\frac{h}{L}, \frac{\sigma_{u}}{U}, \frac{F}{L}, \alpha_{n}\right),
$$

where $A_{\mathrm{z} 0 \mathrm{n}}$ is the neutral-equilibrium constant of $A_{\mathrm{z} 0}$. In AOSIS, we set $A_{\mathrm{z} 0}$ to be 0.011 .

Smith (1981) assumed that the transition from smooth to rough is gradual rather than with a first-order discontinuity and suggested a simple transition as

$$
z_{0 \mathrm{~m}}=z_{0 \mathrm{~m}}(\text { smooth })+z_{0 \mathrm{~m}}(\text { rough }) .
$$

Finally, taking this into consideration, we estimate $z_{0 \mathrm{~m}}$ in AOSIS as

$$
z_{0 \mathrm{~m}}=\frac{A_{\mathrm{z} 0}}{\sqrt{1-\tau_{w} \tau^{-1}}} \frac{u_{*_{a}}^{2}}{g}+\frac{0.11 \nu_{a}}{u_{*_{a}}} .
$$

In comparison to the velocity roughness length, the scalar roughness length is more complicated. It is parameterized in terms of $R_{r}$. Using the sublayer transfer and surface renewal theory, Liu et al. (1979) analyzed field data and suggested that

$$
\begin{aligned}
& z_{0 \mathrm{~h}} \frac{u_{*_{a}}}{\nu_{a}}=a_{1} R_{r}^{b_{1}}, \\
& z_{0 \mathrm{q}} \frac{u_{*_{a}}}{\nu_{a}}=a_{2} R_{r}^{b_{2}},
\end{aligned}
$$

where $a_{1}, b_{1}, a_{2}$, and $b_{2}$ are constants that differ for different ranges of $R_{r}$. Fairall et al. (2003) offered a simpler relationship than that of Liu et al. (1979) to calculate the scalar roughness length. By analyzing the COARE-plus and HEXOS data, they adopted the following empirical formula:

$$
z_{0 \mathrm{~h}}=z_{0 \mathrm{q}}=\min \left(1.1 \times 10^{-4}, 5.5 \times 10^{-5} R_{r}^{-0.6}\right) .
$$

In summary, the parameters and coefficients used by AOSIS are listed in Table 1.

\section{g. Numerical procedure}

The numerical procedure for AOSIS is shown in Fig. 3. 
TABLE 1. Parameters and coefficients used by AOSIS.

\begin{tabular}{lll}
\hline \hline Name & \multicolumn{1}{c}{ Value } & \multicolumn{1}{c}{ Definition } \\
\hline$\beta$ & 1.25 & Coefficient for calculating gustiness part of wind speed \\
$z_{i}$ & $600 \mathrm{~m}$ & $\begin{array}{l}\text { Depth of convective boundary layer } \\
\text { von Kármán constant }\end{array}$ \\
$\kappa$ & 0.4 & Gravity acceleration \\
$g$ & $9.81 \mathrm{~m} \mathrm{~s}^{-2}$ & Coefficient for calculating eddy diffusivity \\
$A$ & 0.22 & Average depth of ocean mixed layer \\
$h^{*}$ & $10 \mathrm{~m}$ & Coefficient for calculating depth of ocean mixed layer \\
$m_{1}$ & 4.5 & Coefficient for calculating stability profile functions \\
$A_{u}$ & 10 & Coefficient for calculating stability profile functions \\
$A_{t}$ & 34 & Coefficient for calculating stability profile functions \\
$\nu_{u}$ & 16 & Coefficient for calculating stability profile functions \\
$\nu_{t}$ & 16 & Coefficient for calculating stability profile functions \\
$\beta_{i}$ & 5 & Coefficient for calculating the rate of wave momentum to total stress \\
$\mu$ & 0.25 & Kinematic viscosity of air \\
$\nu_{a}$ & $1.5 \times 10^{-5} \mathrm{~m}^{2} \mathrm{~s}^{-1}$ & Coefficient for wave significant height \\
$A_{\mathrm{zs}}$ & $0.0248 \mathrm{~m}^{-1} \mathrm{~s}^{2}$ & Coefficient for wave significant period \\
$A_{\mathrm{Tp}}$ & $0.55 \mathrm{~m}^{-1} \mathrm{~s}^{2}$ & Coefficient for calculating dynamics roughness length \\
$A_{\mathrm{z} 0}$ & 0.011 & Ocean surface albedo \\
$\alpha_{w}$ & 0.055 & Ocean surface emissivity \\
$\varepsilon_{w}$ & 0.97 & Stefan-Boltzmann constant \\
$\sigma$ & $5.67 \times 10^{-8} \mathrm{~W} \mathrm{~m}^{-2} \mathrm{~K}^{-4}$ & Density of ocean water \\
$\rho_{w}$ & $\approx 1025 \mathrm{~kg} \mathrm{~m}^{-3}$ & Specific heat of air at constant pressure \\
$c_{\mathrm{pa}}$ & $\approx 1.005 \times 10^{3} \mathrm{~J} \mathrm{~kg}^{-1} \mathrm{~K}^{-1}$ & Specific heat of water at constant pressure \\
$c_{\mathrm{pw}}$ & $\approx 3.99 \times 10^{3} \mathrm{~J} \mathrm{~kg}^{-1} \mathrm{~K}^{-1}$ & \\
\hline & &
\end{tabular}

- Step 1: Input of atmospheric forcing data

The input atmospheric data for AOSIS include air temperature, humidity, wind velocity at reference height, precipitation, shortwave downward radiation, and longwave downward radiation at the ocean surface.

- Step 2: Input of ocean data

The input ocean data include SST and $T_{1}$.

- Step 3: Initialization

Set all predetermined constants and assign $w_{g}=$ $0.1 \mathrm{~m} \mathrm{~s}^{-1}, u *_{a}=0.01 U_{a} \mathrm{~m} \mathrm{~s}^{-1}$, and neutral stability transfer coefficients as a first guess.

- Step 4: Roughness length

Compute $c_{p}, \alpha_{p}$ from Eqs. (66) and (57); compute $\tau_{w} / \tau$ from Eq. (55); compute $z_{0 \mathrm{~m}}$ from Eq. (73); compute $R_{r}$ from Eq. (58); and compute $z_{0 \mathrm{q}}, z_{0 \mathrm{~h}}$ from Eq. (76).

- Step 5: Transfer coefficients

Compute $C_{h}, C_{e}$, and $C_{h}$ from Eqs. (11), (12), and (13).

- Step 6: Turbulent fluxes

Compute $S$ from Eq. (8); compute $H_{s}, H_{1}$, and $\tau$ from

Eqs. (4), (5), and (6); and compute $u_{* a}$ from Eq. (16).

- Step 7: Stability functions

Compute $\zeta$ from Eqs. (14) and (15); compute $\Psi_{u}$ and $\Psi_{t}$ from Eq. (48).

- Step 8: Gustiness wind

Compute $W_{*}$ from Eq. (10); compute $w_{g}$ from Eq. (9).

- Step 9: Depth of daily mixed layer

Compute $B$ from Eq. (31) and $h_{1}$ from Eq. (30).

- Step 10: SST scheme

Compute $T_{0}$ from Eqs. (1), (34), (35), (36), and (39).
- Step 11: Iteration

Repeat from step 4 until converge.

- Step 12: Final step

Repeat the main loop step 4.

If SST is a known value, then the steps in green in Fig. 3 are not used.

\section{h. Summary}

In this section, a new atmosphere-ocean interaction scheme is presented. AOSIS is constructed with three basic components (i.e., a two-layer ocean temperature model, a wind-wave model, and a surface flux model).

The justification for the two-layer ocean temperature model is as follows: ocean temperature and salinity are usually well mixed in a shallow layer below the sea surface known as the mixed layer. This layer has a near-neutral stratification. The mixed layer tends to be bounded below by stratified pycnoclines. Within the mixed layer, the vertically uniform distributions of conservative properties are maintained by wind-generated large eddies. The evolution of the mixed layer temperature is determined primarily by solar radiation and the energy fluxes at the upper and lower boundaries of the mixed layer. The changes arising from horizontal advection due to ocean currents are negligible on the time scales concerned in this study. Based on this argument, we divide the ocean into a mixed layer and a deep layer. However, we emphasis the depth of the mixed layer is not constant but varies with time, depending on surface wind 


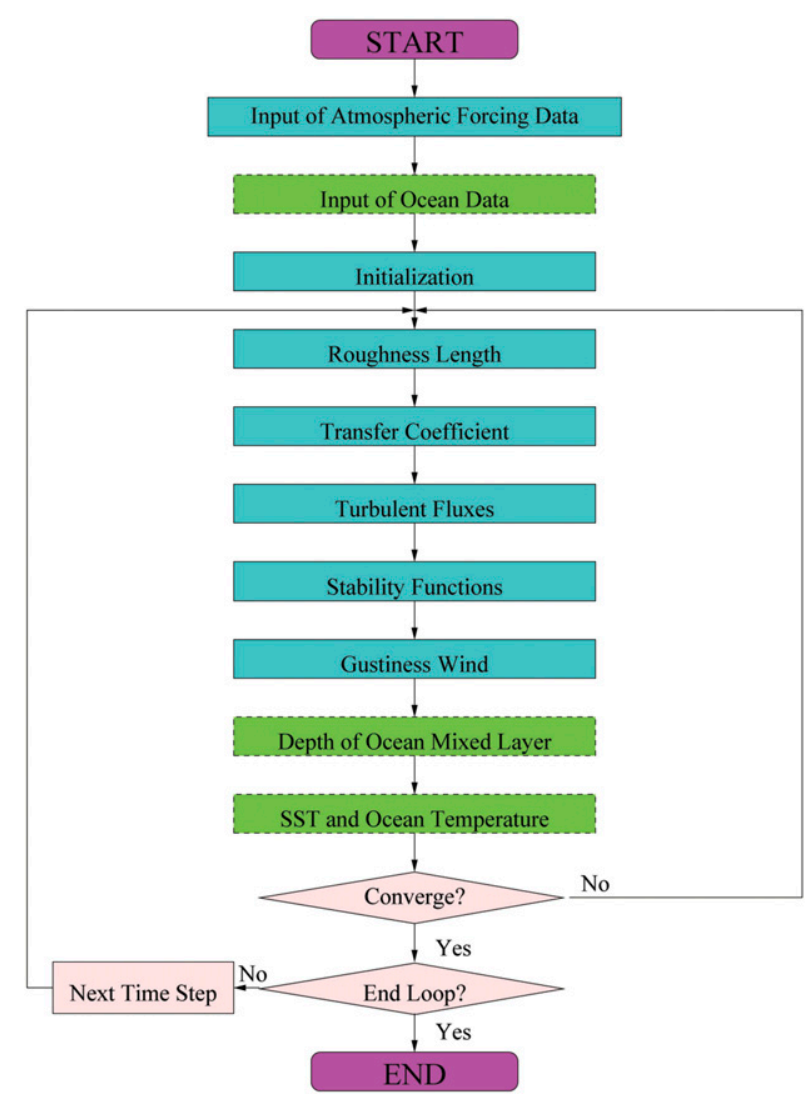

FIG. 3. Flowchart of the numerical procedure for AOSIS. If SST is known, then the steps in green are not used.

stress and buoyancy flux. The mixed layer is shallower for light-wind conditions and vice versa.

The two-layer ocean temperature model simulates SST and the cool-skin and warm-layer effect of ocean mixed layer without the input of ocean bulk temperature observation data, which is required by most one-layer models (e.g., Fairall et al. 1996a,b). It not only considers the heat transport inside the mixed layer but also the sublayer between the mixed layer and the thermocline.

Both eddy and molecular diffusivities affect the transport processes in ocean. For the deep layer, molecular diffusion dominates. In the mixed layer, eddy diffusion dominates. The value of $K_{\mathrm{hw}}$ is allowed to vary with sea state and stability. It is set to be proportioned to $u_{*_{w}}$.

In AOSIS, the Monin-Obukhov similarity functions for the atmospheric boundary layer over the ocean surface are specified according to Fairall et al. (1996b). They give good agreement with the Businger-Dyer formulation for near-neutral stratifications and at the same time satisfy the free-convection limit.

In windy conditions, a sea surface is full of waves resulting in varying aerodynamic roughness lengths in space and time. In turn, the wind profile is affected by surface waves; hence, the growth of waves also depends on the sea state. Thus, the wind profile must be different from that over a flat plate. In AOSIS, we have adapted the approach of relating the stages of wave development to wave age. Snyder et al. (1981) found that the momentum transfer from wind to waves is considerable so that the related wave-induced stress is a substantial fraction of the total stress in the surface layer. This suggests that the drag and other bulk transfer coefficient must depend on the sea state. A widely used empirical expression for roughness length $z_{0 \mathrm{~m}}$ over sea surface was the Charnock (1955) model. Recent research suggested that $z_{0 \mathrm{~m}}$ should be related to wave age and wave slope. In this study, we proposed a new expression for calculating $z_{0 \mathrm{~m}}$ with consideration of waves.

\section{Validation}

In this section, we verify the performance of AOSIS in a stand-alone mode. The scheme is used to simulate sea surface roughness length, sea surface temperature, and energy fluxes. The simulations are compared with observations and independent model results. The two datasets used in this study include the 4-day (26-29 November 1992) Moana Wave data and the 1-yr NCEP data of 1996. A full description of the Moana Wave operations, instruments, and dataset is given by Fairall et al. (1996a,b, 2003). Information about the NCEP data can be found in Kalnay et al. (1996).

Sea surface roughness length and SST are of particular importance to the exchanges at the atmosphere-ocean interface. These two quantities are therefore examined in considerable detail. We first examine the component for roughness length calculation by setting the SST to the observation values without invoking the two-layer ocean temperature model. We then test AOSIS as a whole against observations.

\section{a. The Moana Wave data and the COARE algorithm}

The pivotal role of the tropical oceans in climate variability led to the establishment of the TOGA program. The subsequent identification of the dominance of the Pacific Ocean in climate variability resulted in the COARE program (Lukas and Webster 1992; Fairall et al. 1996b).

The Moana Wave was part of the TOGA COARE program. Ship operations generally consisted of alternating short up- and downwind periods, centered within $10 \mathrm{~km}$ of the Woods Hole Oceanographic Institution's integrated meteorological buoy at $2^{\circ} \mathrm{S}, 156^{\circ} \mathrm{E}$. Flux data were taken during three periods: 11 November-3 December 1992, 17 December 1992-11 January 1993, and 28 January-16 February 1993 . The ship was generally located at $1.7^{\circ} \mathrm{S}$, $156^{\circ} \mathrm{E}$ except for a few days at the beginning of period 2 and the end of period 3 , when it was at $0^{\circ}, 156^{\circ} \mathrm{E}$. 
Fairall et al. (1996b) have developed the COARE 2.5 algorithm to parameterize the air-sea fluxes for the TOGA COARE program. The algorithm follows the Monin-Obukhov similarity theory for near-surface meteorological measurements. The basic structure is an outgrowth of the Liu et al. (1979) method, with various modifications. The modifications include a different specification of the roughness-stress relationship, a gustiness coefficient to account for the additional flux induced by boundary layer scale variability, and profile functions obeying the convective limit but with no adjustment of constants specifying the relationship between the scalar and velocity transfer coefficients. In addition, they have considered the contributions of the sensible heat carried by precipitation, the requirement that the net dry mass flux be zero, and the proper specification of the variables for the sensible and latent heat fluxes. Separate models to account for both the cool-skin and warm-layer effects of bulk sea temperature have been integrated into COARE 2.5 (Fairall et al. 1996b). The algorithm has been tuned to fit the Moana Wave data for wind speed ranging between 0 and $12 \mathrm{~m} \mathrm{~s}^{-1}$. Since the publication of COARE 2.5 in 1996, it has become one of the most frequently used algorithms in the atmosphere-ocean interaction community.

In 2003, COARE 3.0 was published, and the valid range for wind speed was extended to $0-20 \mathrm{~m} \mathrm{~s}^{-1}$. The updates included improvements to the stability functions, shortening the stability iteration, and eliminating the need for a Webb correction to latent heat flux. The wind speed dependence of both velocity and scalar transfer coefficients was changed slightly, particularly above $10 \mathrm{~m} \mathrm{~s}^{-1}$. The modifications were based on published results and 2777 1-h covariance flux measurements in the Environmental Technology Laboratory (ETL) inventory. For an overall mean, the algorithm agrees with the data to within a few percent for stress and latent heat flux. The agreement is also excellent when the bulk and directly measured fluxes are averaged in bins of neutral wind speed at $10-\mathrm{m}$ height. For more detail about COARE 3.0, see Fairall et al. (2003). The output variables of COARE 3.0 using Moana Wave data are listed in Table 2. These variables are used together with the Moana Wave observed data as Moana Wave data to validate AOSIS.

\section{b. NCEP-NCAR reanalysis data}

The NCEP-National Center for Atmospheric Research (NCAR) reanalysis data are produced by the National Centers for Environmental Prediction and National Center for Atmospheric Research through the "reanalysis" project that began in 1991. It has records of global analysis of atmospheric fields from 1957 up to the present. The project
TABLE 2. Names, definitions, and dimensions of COARE 3.0 output variables.

\begin{tabular}{lll}
\hline \hline Name & \multicolumn{1}{c}{ Definition } & \multicolumn{1}{c}{ Unit } \\
\hline time & $\begin{array}{c}\text { Date and time } \\
\text { (yyyymmddhhnnss.ss) }\end{array}$ & $\mathrm{GST}^{\mathrm{b}}$ \\
csh & SHF & $\mathrm{W} \mathrm{m}^{-2}$ \\
clh & LHF & $\mathrm{W} \mathrm{m}^{-2}$ \\
sst & Sea surface temperature & ${ }^{\circ} \mathrm{C}$ \\
tstr & Total stress & $\mathrm{N} \mathrm{m}^{-2}$ \\
wbar & Webb vertical velocity & $\mathrm{m} \mathrm{s}^{-1}$ \\
rhf & Heat flux due to rainfall & $\mathrm{W} \mathrm{m}^{-2}$ \\
cst & Cool skin temperature & ${ }^{\circ} \mathrm{C}$ \\
dwt & Diurnal warming of surface layer & ${ }^{\circ} \mathrm{C}$ \\
ddw & Depth of diurnal warming & $\mathrm{m}$ \\
csth & Cool skin thickness & $\mathrm{m}$ \\
gusv & Gustiness velocity & $\mathrm{m} \mathrm{s}$ \\
\hline
\end{tabular}

${ }^{a}$ The format for time is given as the date with four-digit year (yyyy), two-digit month (mm), and two-digit day (dd), followed by the time with two-digit hours (hh), two-digit minutes (nn), and four-digit seconds (ss.ss).

${ }^{\mathrm{b}}$ GST is Guam standard time.

involves the recovery of land surface, ship, rawindsonde, pibal, aircraft, satellite, and other data. Quality control and data assimilation were carried out with a data assimilation system that is kept unchanged over the reanalysis period (Kalnay et al. 1996).

Although the NCEP-NCAR reanalysis uses a frozen state-of-the-art global data assimilation system and a database as complete as possible, not all the data are observations. Output variables are classified into four categories, depending on the relative influence of the observation data and the model data on the reanalyzed variables. Class A variables are generally well defined by the observations and, given the statistical interpolation of observations and first guess, provide an estimate of the state of the atmosphere better than would be obtained using observations alone. Hence, it is the most reliable class (e.g., upper-air temperature and wind). Class B variables are partially defined by the observations but are also strongly influenced by the model characteristics (e.g., humidity and air surface temperature). Class $\mathrm{C}$ variables are not directly observed, or their observations are not currently assimilated into the present analysis system. Instead, they are derived solely from the model fields forced by the data assimilation to remain close to the atmosphere (e.g., clouds and precipitation). Finally, class D variables represent fields that are fixed from climatological values and do not depend on the model (e.g., plant resistance and land-sea mask). Nevertheless, a comparison of these variables with observations shows that they generally contain considerable useful information. The NCEP data used for AOSIS validation are listed in Table 3. 
TABLE 3. Summary of NCEP data used for AOSIS validation. Variable names, definitions, dimensions, and classes are listed.

\begin{tabular}{|c|c|c|c|}
\hline Name & Definition & Unit & Class \\
\hline tair2m & Air temperature at $2 \mathrm{~m}$ & $\mathrm{~K}$ & A \\
\hline uwnd10 & $u$ wind at $10 \mathrm{~m}$ & $\mathrm{~m} \mathrm{~s}^{-1}$ & A \\
\hline vwnd10 & $v$ wind at $10 \mathrm{~m}$ & $\mathrm{~m} \mathrm{~s}^{-1}$ & A \\
\hline Pr_wtr & Precipitable water for entire atmosphere & $\mathrm{kg} \mathrm{m}^{-2}$ & $\mathrm{~B}$ \\
\hline pres & Surface pressure & $\mathrm{Pa}$ & $\mathrm{B}$ \\
\hline rhum & Relative humidity at sigma level 995 & $\%$ & $\mathrm{~B}$ \\
\hline shum & Specific humidity & $\mathrm{kg} \mathrm{kg}^{-1}$ & $\mathrm{~B}$ \\
\hline dlwrf & Downward longwave radiation flux at surface & $\mathrm{W} \mathrm{m}^{-2}$ & $\mathrm{C}$ \\
\hline dswrf & Downward solar radiation flux at surface & $\mathrm{W} \mathrm{m}^{-2}$ & $\mathrm{C}$ \\
\hline gflux & Ground heat flux at surface & $\mathrm{W} \mathrm{m}^{-2}$ & $\mathrm{C}$ \\
\hline lhtfl & LHF at surface & $\mathrm{Wm}^{-2}$ & $\mathrm{C}$ \\
\hline shtfl & SHF at surface & $\mathrm{W} \mathrm{m}^{-2}$ & $\mathrm{C}$ \\
\hline skt & Daily SST/land skin temperature & $\mathrm{K}$ & $\mathrm{C}$ \\
\hline sfcr & Surface roughness length & $\mathrm{m}$ & $\mathrm{D}$ \\
\hline
\end{tabular}

\section{c. Offline point validation without SST scheme}

\section{1) WIND-WAVE EFFECT}

We now examine the performance of the AOSIS windwave component, together with three other roughness length parameterizations, in modeling sea surface aerodynamic characteristics (e.g., $z_{0 \mathrm{~m}}$, wave age, and shear stress). Table 4 is a summary of the four $z_{0 \mathrm{~m}}$ parameterizations to be tested.

AOSIS, Taylor-Yelland (TY01), and Oost-KomenJacobs-Oort (OKJO02), using the Moana Wave data as input, are used to calculate wave age $c_{p} / u_{*}$, total momentum stress $\tau$, wave-induced stress $\tau_{w}$, and the ratio $\tau_{w} / \tau$ as functions of $10-\mathrm{m}$ wind speed. The results are shown in Fig. 4. As can be seen, the estimated wave age from all three schemes have a turning point at around $U_{10 \mathrm{n}}=3 \mathrm{~m} \mathrm{~s}^{-1}$. Under light-wind conditions $\left(U_{10 \mathrm{n}} \leq\right.$ $3 \mathrm{~m} \mathrm{~s}^{-1}$ ), wave age increases quickly from about 15 to 26 with wind velocity. For stronger winds, wave age drops slowly from about $26\left(3-5 \mathrm{~m} \mathrm{~s}^{-1}\right)$ to $22\left(10 \mathrm{~m} \mathrm{~s}^{-1}\right)$. The AOSIS estimation falls between those of TY and OKJO. All estimates are almost the same when wind speed is below $1 \mathrm{~m} \mathrm{~s}^{-1}$. The line in Fig. $4 \mathrm{a}\left(c_{p} / u_{*}=28\right)$ is the case when wave is well developed.

The estimated total momentum stress $\tau$ is similar for all three schemes (Fig. 4b): it increases with wind speed. The AOSIS estimates of $\tau$ are somewhat smaller than the TY01 estimates but larger than the OKJO02 estimates. The differences among the schemes become larger as wind speed increases. The wave-induced stress $\tau_{w}$ has a similar pattern as $\tau$ but is smaller than the latter (Fig. 4c). The estimated ratio $\tau_{w} / \tau$ reaches a minimum at around $U_{10 \mathrm{n}}=3 \mathrm{~m} \mathrm{~s}^{-1}$. For weaker winds, the ratio increases from about 0.4 to 0.75; and for stronger winds, it increases to 0.5 at $U_{10 \mathrm{n}}=10 \mathrm{~m} \mathrm{~s}^{-1}$.

\section{2) Roughness ReYNOLDS NUMBER}

Roughness Reynolds number is useful in characterizing flow regimes over rough surfaces. A flow over the ocean surface is considered to be aerodynamically smooth if $R_{r}<0.13$, which occurs when $U_{10 \mathrm{n}} \leq 2 \mathrm{~m} \mathrm{~s}^{-1}$, and aerodynamically rough when $R_{r}>2.5$, which occurs when $U_{10 \mathrm{n}} \geq 8 \mathrm{~m} \mathrm{~s}^{-1}$. In the former situation, the roughness elements on the surface can be considered to be irrelevant, and the surface stress is a result of viscous shear.

Figure 5a shows the relationship between $R_{r}$ and wind speed, computed using different schemes. As wind speed decreases, $R_{r}$ estimated from all four schemes approaches a constant value of about 0.11 . The results agree quite well with earlier studies (e.g., Kraus and Businger 1994). Obviously, $R_{r}$ increases with wind speed for all schemes. However, the TY01 estimates of $R_{r}$ increase the fastest, while the OKJO02 estimates the slowest. The AOSIS and COARE estimates are similar.

\section{3) ROUGHNESS LENGTH}

The sea surface roughness length $z_{0 \mathrm{~m}}$ is often crudely related to waves. In COARE, the wind-wave influence is not included, while in AOSIS, TY01, and OKJO02, the effect of waves is treated differently. As shown in Fig. 5b, all four schemes show an increasing $z_{0 \mathrm{~m}}$ with wind speed from about $0.00004 \mathrm{~m}$ at light winds to about $0.001-0.004 \mathrm{~m}$ at $10 \mathrm{~m} \mathrm{~s}^{-1}$. The AOSIS and COARE values are close, both lower than the TY01's and higher than the OKJO02's. The AOSIS values are higher than the COARE's. For example, for $U_{10 \mathrm{n}}=$ $8 \mathrm{~m} \mathrm{~s}^{-1}, z_{0 \mathrm{~m}}$ is $0.00016,0.00011,0.00028$, and $0.00008 \mathrm{~m}$, respectively, for AOSIS, COARE, TY01, and OKJO02.

\section{4) DRAG TRANSFER COEFFICIENT AND SCALAR TRANSFER COEFFICIENT}

Figure $5 \mathrm{c}$ shows the drag transfer coefficient $C_{d}$ estimated from the four schemes for neutral boundary 
TABLE 4. Summary of four different parameterizations for sea surface roughness length $z_{0 \mathrm{~m}}$. The variables are defined in section 2 .

\begin{tabular}{|c|c|c|c|}
\hline Scheme & Formula & Wave effect & Reference \\
\hline AOSIS & $z_{0 \mathrm{~m}}=\frac{A_{z 0}}{\sqrt{1}} \frac{u_{*_{a}}^{2}}{\sigma}+\frac{0.11 \nu_{a}}{u *}$ & Yes & - \\
\hline TY01 & $\begin{aligned} & \sqrt{1-\tau_{w} \tau^{-1}} g \quad u *_{a} \\
z_{0 \mathrm{~m}}= & A Z_{\mathrm{sw}}\left(\frac{Z_{\mathrm{sw}}}{L_{p}}\right)^{B}+\frac{0.11 \nu_{a}}{u_{* a}}\end{aligned}$ & Yes & Taylor and Yelland (2001) \\
\hline OKJO02 & $z_{0 \mathrm{~m}}=\frac{50}{2 \pi} L_{p}\left(\frac{c_{p}}{u *_{a}}\right)^{-4.5}+\frac{0.11 \nu_{a}}{u_{*_{a}}}$ & Yes & Oost et al. (2002) \\
\hline COARE & $z_{0 \mathrm{~m}}=\alpha_{\mathrm{Ch}} \frac{u_{*_{a}}^{2}}{g}+\frac{0.11 \nu_{a}}{u_{*_{a}}}$ & No & Fairall et al. (2003) \\
\hline
\end{tabular}

layers. For all schemes, $C_{d}$ increases almost linearly with $U_{10 \mathrm{n}}$ for $U_{10 \mathrm{n}}>5 \mathrm{~m} \mathrm{~s}^{-1}$. This characteristic of $C_{d}$ is well known. There is a small decrease in $C_{d}$ at wind speeds below $4 \mathrm{~m} \mathrm{~s}^{-1}$, as suggested by Smith (1988). The AOSIS and COARE estimates of $C_{d}$ are similar, both lower than the estimates of TY01 but higher than the estimates of OKJO02.

The accuracy of surface energy flux estimates is greatly affected by the accuracy of the bulk scalar transfer coefficient $C_{e}$. For instance, a $10 \%$ uncertainty
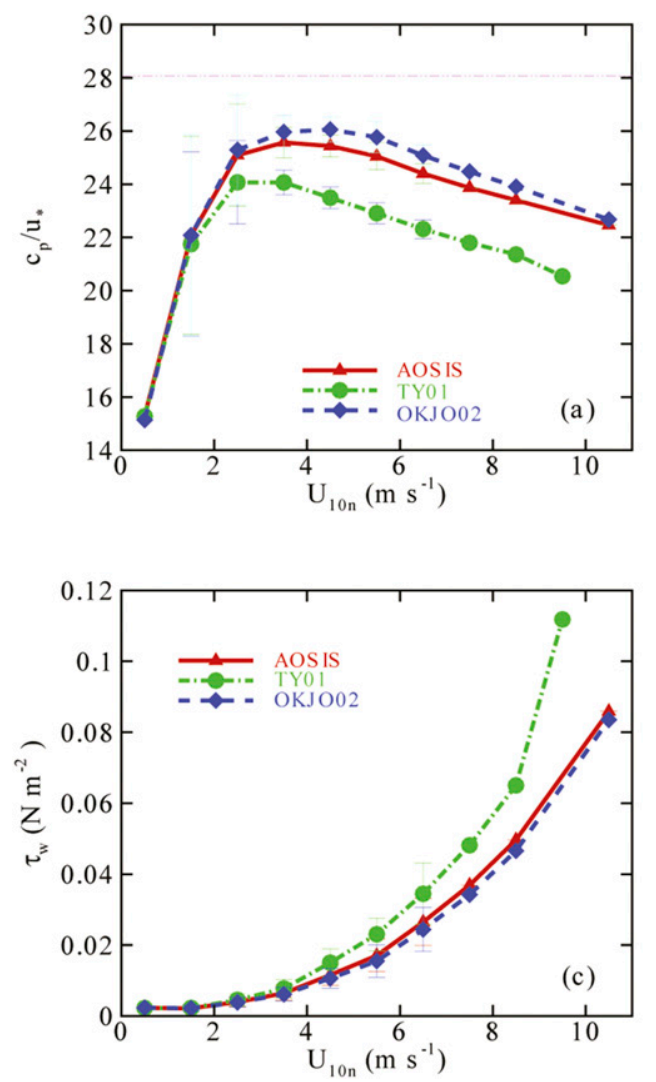

in this coefficient would result approximately in a $10 \mathrm{~W} \mathrm{~m}^{-2}$ uncertainty in latent heat flux. Figure $5 \mathrm{~d}$ shows the bulk transfer coefficient for moisture (between surface and $10 \mathrm{~m}$ ) under neutral stability conditions, $C_{e}$, estimated from the four schemes. As shown, the AOSIS and COARE estimates of $C_{e}$ have a minimum at about $U_{10 \mathrm{n}}=2-3 \mathrm{~m} \mathrm{~s}^{-1}$; it increases toward lower wind speed. This behavior of $C_{e}$ has been confirmed by Fairall et al. (2003) with about $700 \mathrm{~h}$ of data below $2.5 \mathrm{~m} \mathrm{~s}^{-1}$. For stronger wind speed, $C_{e}$ increases
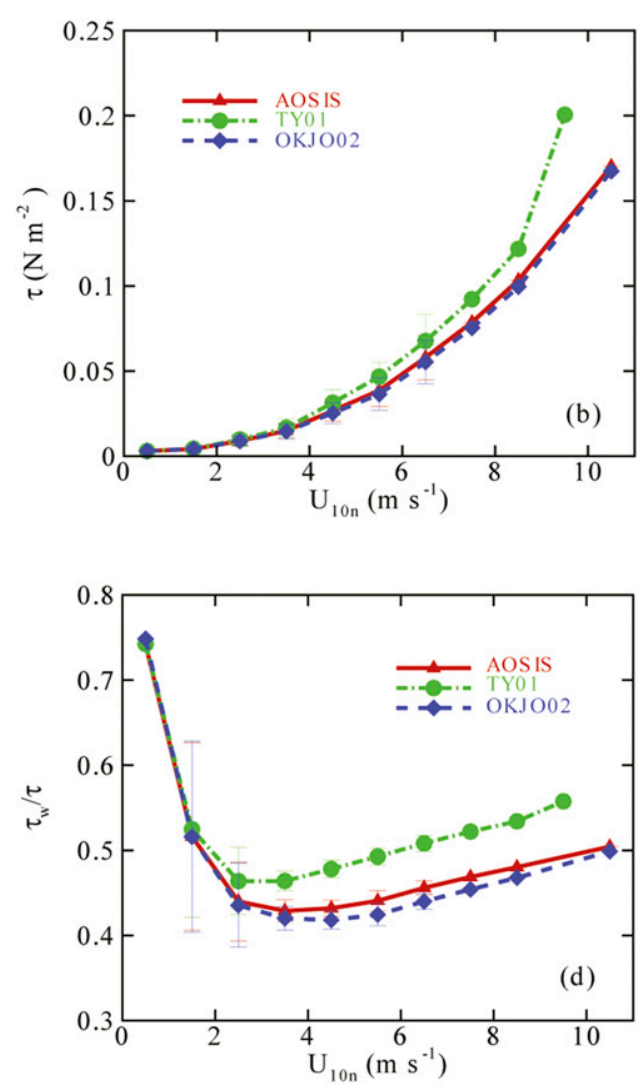

FIG. 4. (a) Wave age $c_{p} / u_{*_{a}}$; (b) total momentum stress $\tau$; (c) wave-induced stress $\tau_{w}$; and (d) the ratio $\tau_{w} / \tau$, as functions of the wind speed at $10 \mathrm{~m} U_{10}$, estimated from different schemes: AOSIS (red line), TY01 (green line), and OKJO02 (blue line). The simulated data have been averaged over wind speed bins with $1 \mathrm{~m} \mathrm{~s}^{-1}$ bin width. 

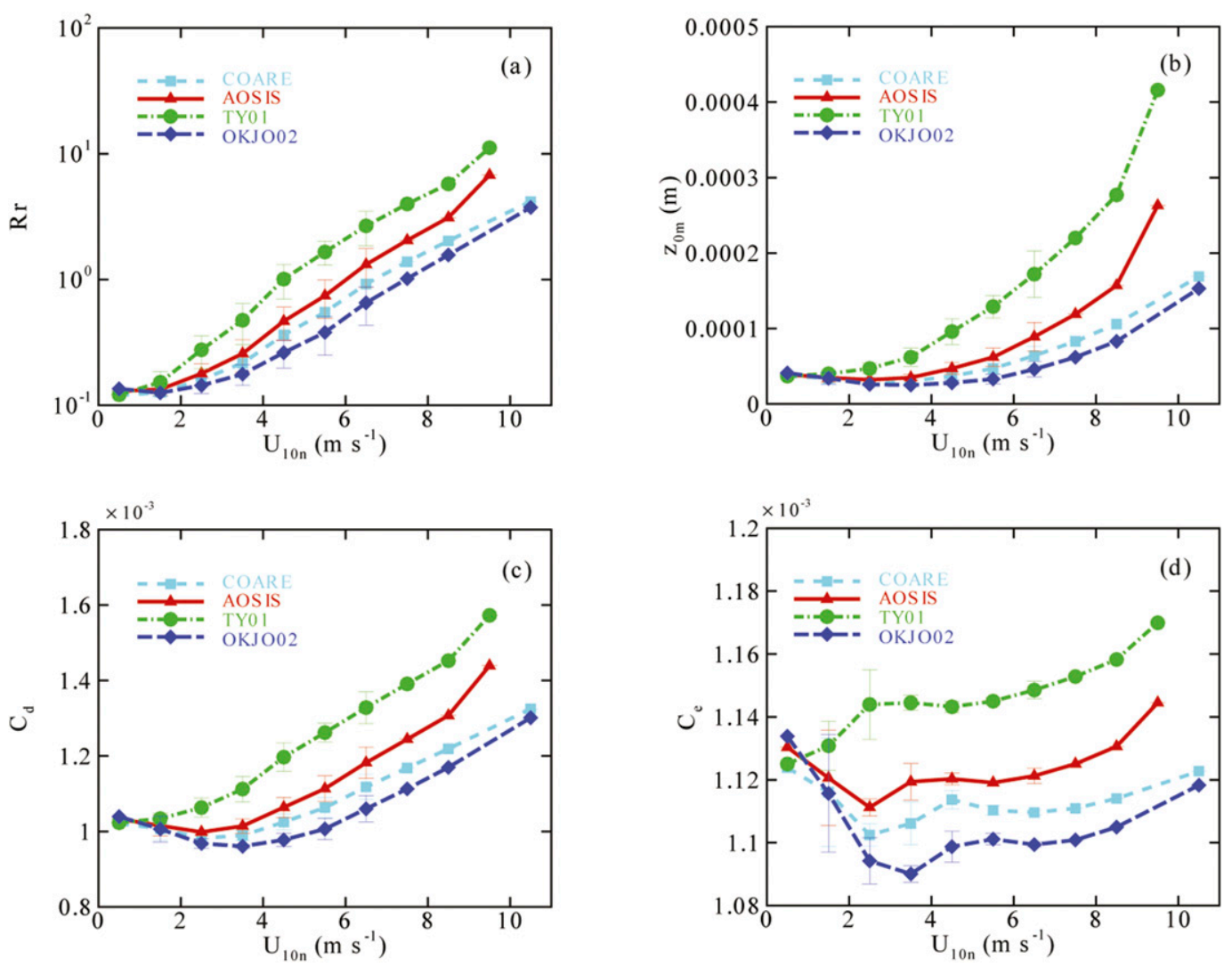

FIG. 5. (a) Roughness Reynolds number $R_{r}$; (b) aerodynamic roughness length $z_{0 \mathrm{~m}}$; (c) drag transfer coefficient $C_{d}$; and (d) moisture transfer coefficient $C_{e}$, as functions of the wind speed at $10 \mathrm{~m} U_{10 \mathrm{n}}$, for four different schemes using the Moana Wave data: AOSIS (red line), COARE (cyan line), TY01 (green line), and OKJO02 (blue line). The simulated data have been averaged over wind speed bins with $1 \mathrm{~m} \mathrm{~s}^{-1}$ bin width.

steadily toward higher wind speed. This is in agreement with the ETL1999 data (Fairall et al. 2003).

The values of $C_{e}$ from the four schemes for $U_{10 \mathrm{n}}$ between 0 and $11 \mathrm{~m} \mathrm{~s}^{-1}$ are $1.124( \pm 0.023) \times 10^{-3}$ for AOSIS, $1.113( \pm 0.011) \times 10^{-3}$ for COARE, 1.146 $( \pm 0.024) \times 10^{-3}$ for TY01, and $1.106( \pm 0.028) \times 10^{-3}$ for OKJO02. These values are in reasonable agreement with those reported by Smith (1989), $C_{e}=1.2( \pm 0.1) \times 10^{-3}$ for winds between 4 and $14 \mathrm{~m} \mathrm{~s}^{-1}$, and by Garratt (1992) and Smith et al. (1996), $1.1 \times 10^{-3} \pm 15 \%$ for winds between 3 and $20 \mathrm{~m} \mathrm{~s}^{-1}$. Fairall et al. (2003) suggested that for winds above $5 \mathrm{~m} \mathrm{~s}^{-1}, C_{e}$ is nearly a constant of $1.15 \times 10^{-3}$ within $5.3 \%$.

\section{d. Offline point validation with SST scheme}

In this section, the AOSIS SST scheme described in section 2 will be tested against COARE 3.0 (Fairall et al. 2003). In principle, SST should be measured at the atmosphere-ocean interface using sensors such as an infrared radiometer. However, such measurements require careful corrections for reflected atmospheric radiance. This procedure places considerable demands on the calibration accuracy and the stability of the device. Inexpensive, accurate, and reliable instruments that can be used routinely are not available, so we must use in situ sensors placed in the water. These so-called bulk temperature sensors may use ship intakes at 2-10-m depth or floating thermistors at a few centimeters depth. To obtain the correct SST, COARE 3.0 used the warm-layer and cool-skin schemes to correct the bulk temperatures:

$$
T_{s}=T_{m}(z)-\Delta T_{c}+\Delta T_{w}(z),
$$

where $T_{m}(z)$ is the subsurface in situ temperature measurement at depth $z, \Delta T_{c}$ is the cool-skin correction, and $\Delta T_{m}(z)$ is the warm-layer correction.

The warm layer is a region in the upper few meters of the ocean where solar radiation has caused significant warming relative to the deeper ocean temperature. Warm layers occur during the day when temperature 
stratification caused by the absorption of the solar flux is sufficiently strong to suppress shear-induced mixing and can be on the order of $3 \mathrm{~K}$. Thus, the warm layer is a diurnal phenomenon. The cool skin is a layer in the upper few millimeters of the ocean caused by the combined cooling effects of the net longwave radiation $R_{\mathrm{nl}}$, the sensible heat flux $H_{s}$ and the latent heat flux $H_{l}$. The cool-skin effect is on the order of $0.1-0.5 \mathrm{~K}$ and is almost always present, although the cool-skin effect may be compensated by the presence of a warm layer.

The basic physics of the cool skin was described by Saunders (1967). The total cooling at the interface $Q$ is given by

$$
-Q=R_{\mathrm{nl}}-H_{s}-H_{l},
$$

where $R_{\mathrm{nl}}=R_{\downarrow 1}-R_{\uparrow 1}$ and a positive value for $Q$ represents cooling of the water. The cool-skin temperature change is confined to a region of thickness $\delta$ under the ocean surface, which is referred to as the ocean molecular sublayer. In this sublayer, the temperature gradient is defined by molecular thermal conductive processes:

$$
\left.\kappa_{m} \frac{\partial T}{\partial z}\right|_{0}=Q
$$

where $\kappa_{m}$ is the thermal conductivity of water, $z$ is the vertical ordinate (zero at the surface and positive downward), and $T$ is the temperature profile. From Eq. (79), one can see that

$$
\Delta T_{c} \cong Q \frac{\delta}{\kappa_{m}}
$$

where $\Delta T_{c}$ is positive if the surface is cooler than the bulk. The $\delta$ can be estimated by assuming that it is proportional to the Kolmogorov microscale (Panofsky and Dutton 1984):

$$
\delta \cong\left(\nu_{w}^{3} / \varepsilon\right)^{1 / 4},
$$

where $\nu_{w}$ is the kinematic viscosity of water and $\varepsilon$ is the rate of dissipation of water turbulent kinetic energy.

In the warm-layer model, Fairall et al. (1996a) used a much simplified form of the Price et al. (1986) formulation that ignores full mixed layer dynamics (e.g., seasonal thermocline entrainment). These can be crudely summarized by assuming that once the stratified warm layer forms shortly after $\delta S_{w}$ (the mean solar heat instantaneously absorbed in the warm layer) exceeds $Q$, then the temporal integrals of the surface fluxes induce changes in the near-surface temperature and current that are confined to a depth of $D_{w}$ :
TABLE 5. Statistics of AOSIS simulated SST, SHF, and LHF compared with the corresponding quantities of COARE 3.0.

\begin{tabular}{lrcc}
\hline \hline & SST $(\mathrm{K})$ & $\mathrm{SHF}\left(\mathrm{W} \mathrm{m}^{-2}\right)$ & $\mathrm{LHF}\left(\mathrm{W} \mathrm{m}^{-2}\right)$ \\
\hline Mean AOSIS & 302.18 & 6.78 & 93.71 \\
Mean COARE & 302.28 & 6.93 & 87.17 \\
Fractional bias & 0.00 & 0.02 & 0.07 \\
Degree of agreement & 0.86 & 0.96 & 0.87 \\
Correlation coef & 0.82 & 0.92 & 0.78 \\
\hline
\end{tabular}

$$
\begin{aligned}
\Delta T_{w} & =\frac{2 \int\left(\delta S_{w}-Q\right) d t}{\rho_{w} c_{\mathrm{pw}} D_{w}}=\frac{2 I_{s}}{\rho_{w} c_{\mathrm{pw}} D_{w}}, \\
\Delta u_{w} & =\frac{2 \int u_{*_{w}}^{2} d t}{D_{w}}=\frac{2 I_{r}}{D_{w}},
\end{aligned}
$$

where $u_{* w}$ denotes the magnitude of the current; $\Delta T_{w}$ is the total temperature change across the warm layer. The depth is determined by requiring the bulk Richardson number to be no greater than a critical value, $R_{\text {ic }}=0.65$ :

$$
D_{w}=\left(2 R_{\mathrm{ic}}\right)^{1 / 2} \frac{I_{\tau}}{\left(\alpha_{B} g I_{S} / \rho_{w} c_{\mathrm{pw}}\right)^{1 / 2}} .
$$

\section{1) Statistical AnAlysis}

The quantitative measures for the AOSIS performance in simulating SST and surface heat fluxes are given in Table 5. The statistical analysis includes the mean values of AOSIS and COARE, fractional bias $\left(f_{b}\right)$, degree of agreement $\left(D_{a}\right)$, and correlation coefficient $(r)$, defined as follows:

$$
\begin{aligned}
f_{b} & =\frac{2(\bar{A}-\bar{O})}{\bar{A}+\bar{O}}, \\
D_{a} & =1-\frac{\sum\left(A_{i}-O_{i}\right)^{2}}{\sum\left(\left|A_{i}-\bar{O}\right|+\left|O_{i}-\bar{O}\right|\right)^{2}}, \\
r & =\frac{n-1}{n} \frac{\sum\left[\left(A_{i}-\bar{A}\right)\left(O_{i}-\bar{O}\right)\right]}{\sqrt{\sum\left(A_{i}-\bar{A}\right)^{2} \sum\left(O_{i}-\bar{O}\right)^{2}}},
\end{aligned}
$$

where $A_{i}$ represents an AOSIS simulated quantity and $\bar{A}$ its mean value, $O_{i}$ represents an observed or other scheme simulated quantity and $\bar{O}$ its mean value, and $n$ is the sample size. Fractional bias compares the longterm means of two samples without considering the importance of single time step values. A high correlation coefficient means that the two samples are close in phase; that is, the same physical processes govern the variations in both samples. Degree of agreement is an 

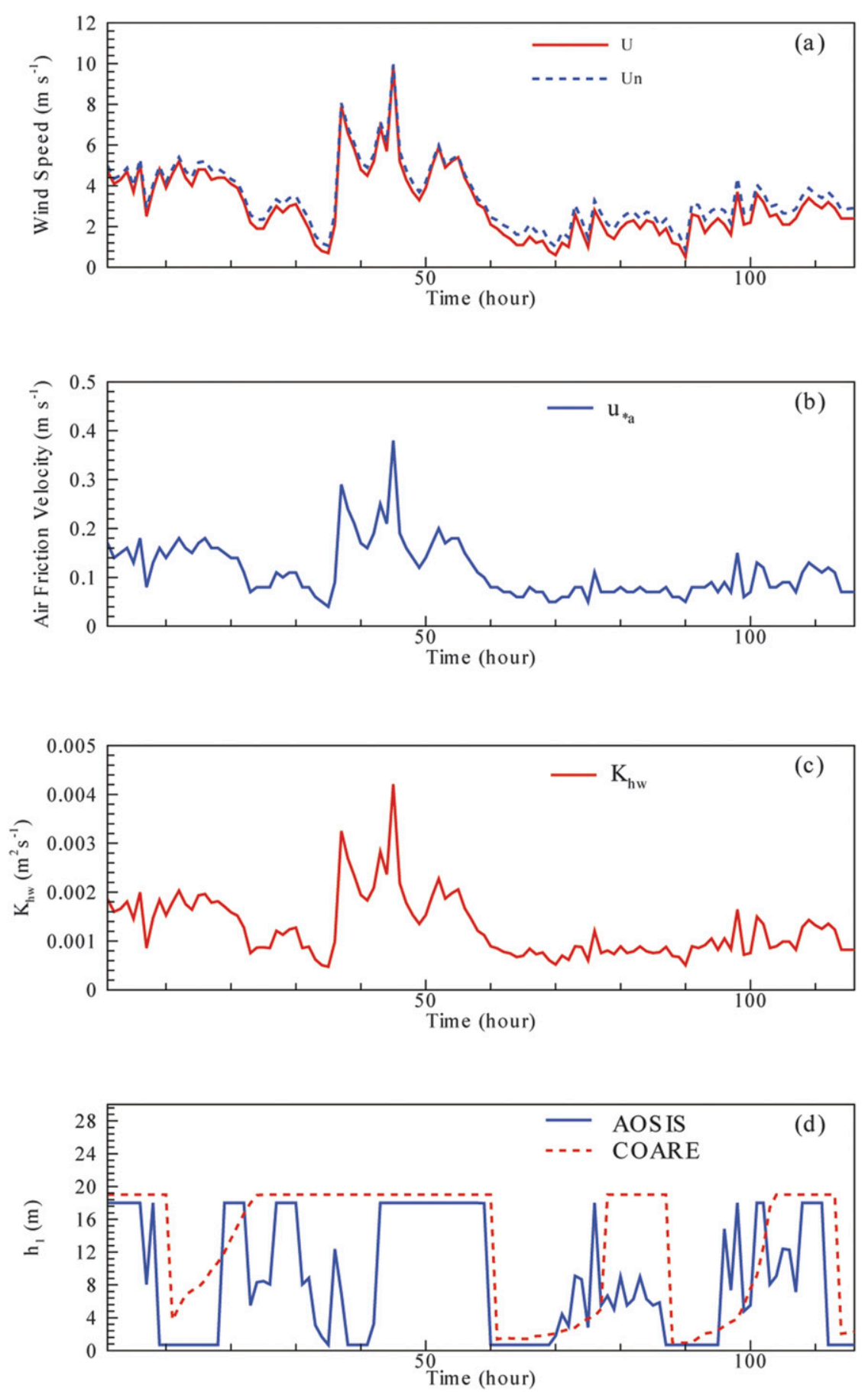

FIG. 6. (a) Wind speed, (b) air friction velocity, (c) eddy transfer coefficient, and (d) depth of mixed layer computed from AOSIS with Moana Wave data.

indicator for the deviation of one sample (e.g., model results) from the other (e.g., observation).

\section{2) MoANA WAVE: RESULTS AND DISCUSSION}

The AOSIS SST scheme is computationally efficient. It takes about four time steps to converge. In Figs. 6 and 7, wind speed and the AOSIS estimates of friction velocity, eddy transfer coefficient, depth of mixed layer, heat fluxes, temperature of different layers, and SST are shown. As Fig. $6 \mathrm{c}$ shows, $K_{\mathrm{hm}}$ is directly proportional to $u_{* a}$, as expected from Eq. (26). When wind is strong, $K_{\mathrm{hm}}$ is large, and ocean mixing is strong. As a consequence, the changes 

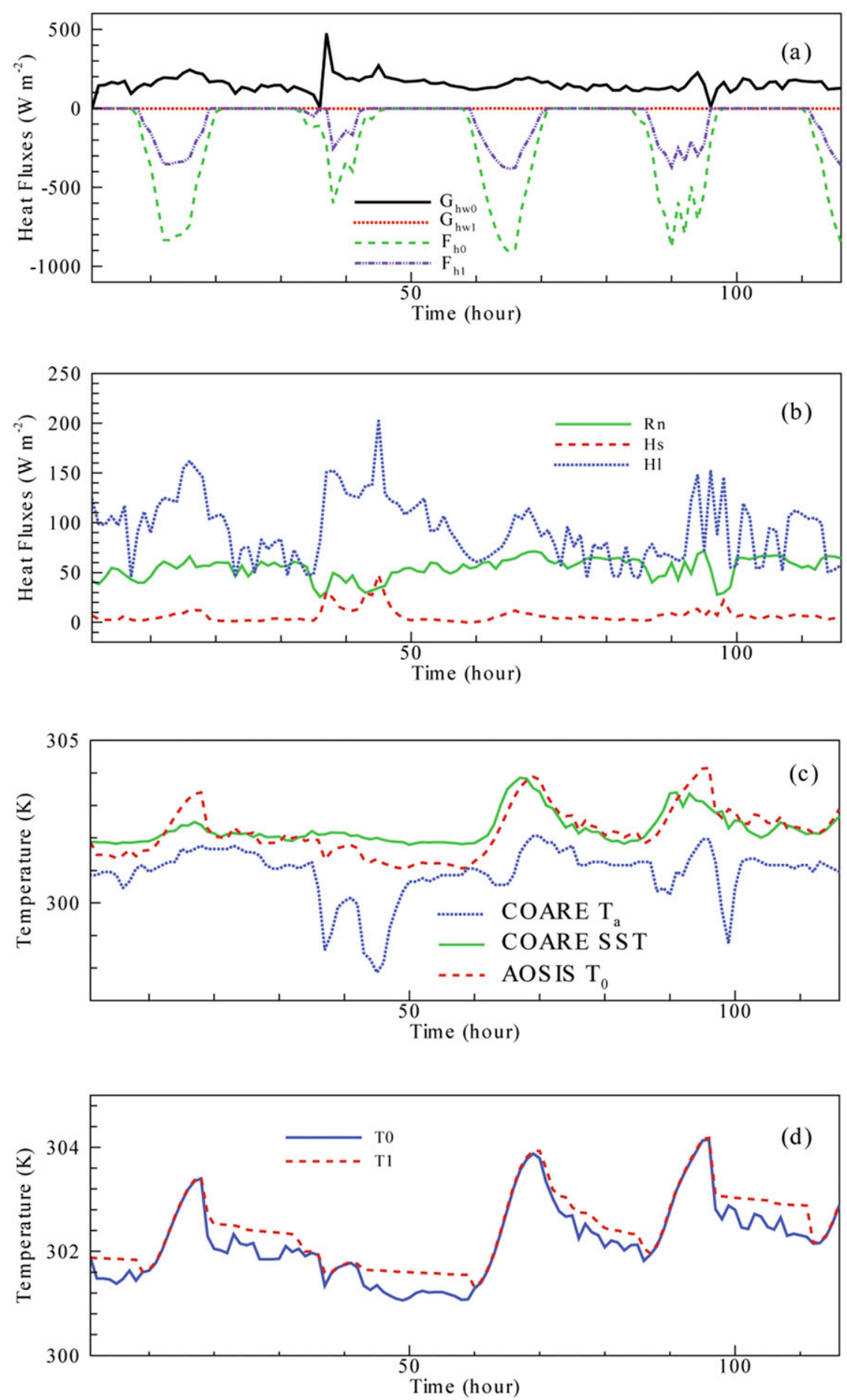

FIG. 7. (a) Heat fluxes $G_{\mathrm{hw} 0}, G_{\mathrm{hw} 1}, F_{\mathrm{h} 0}$, and $F_{\mathrm{h} 1}$; (b) heat fluxes $R_{n}, H_{s}$, and $H_{1}$; (c) SST $T_{0}$; and (d) temperature $T_{0}$ and $T_{1}$ computed from AOSIS with Moana Wave data. AOSIS SST $\left(T_{0}\right)$ is compared with COARE SST and $T_{a}$ in (c).

in ocean temperature are more rapid. The average $K_{\mathrm{hm}}$ in Moana Wave case is $3.27 \times 10^{-3} \mathrm{~m}^{2} \mathrm{~s}^{-1}$.

In AOSIS, the maximum and minimum of the mixed layer depth $h_{1}$ are set to be 0.65 and $18 \mathrm{~m} \mathrm{~s}^{-1}$, respectively.
The AOSIS simulated $h_{1}$ (Fig. 6d) is similar to that of COARE. However, the AOSIS simulation shows more details and is more consistent with the variations of solar radiation $F_{\mathrm{h} 0}$ (Fig. 7a). 

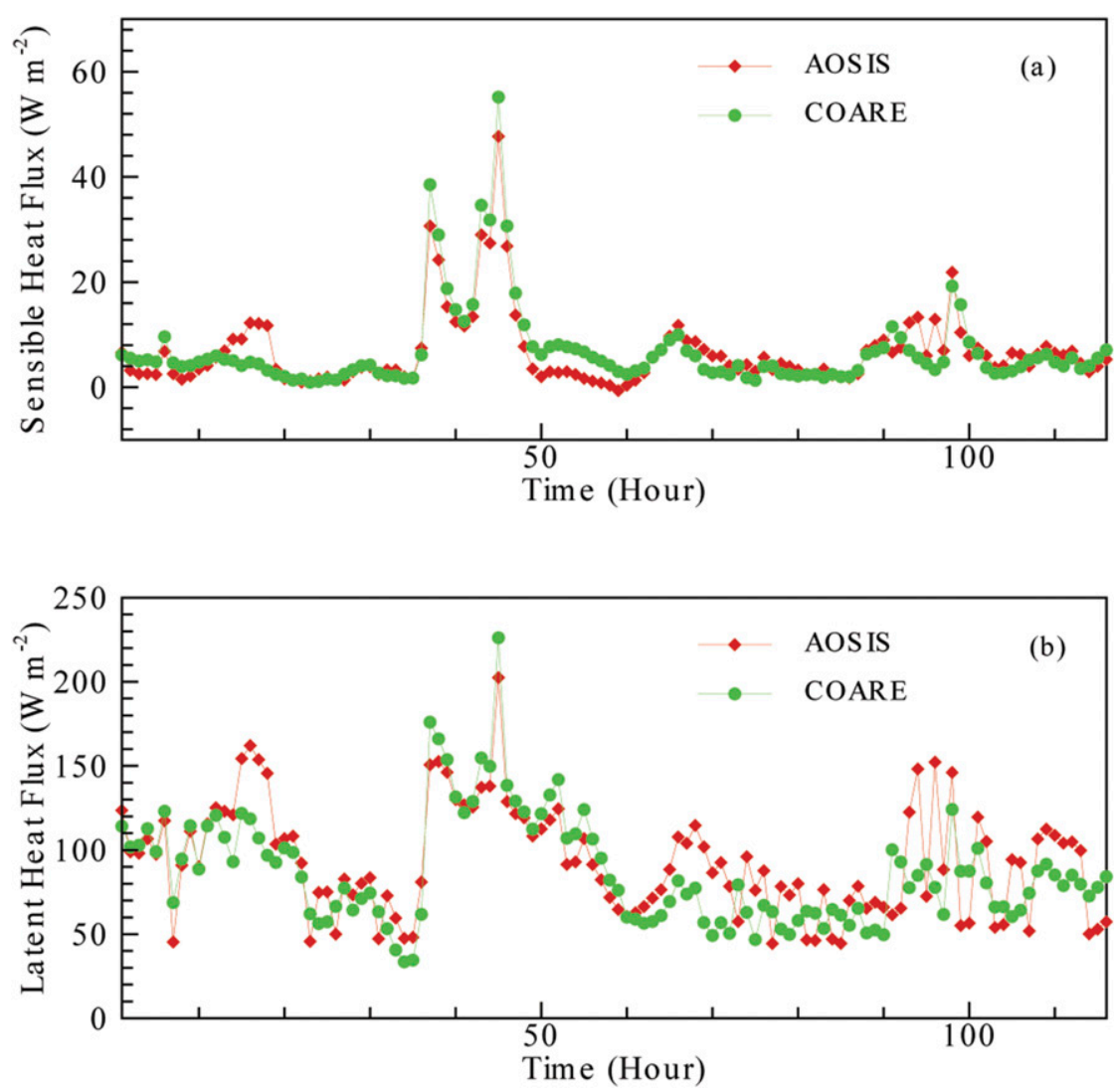

FIG. 8. Comparison of AOSIS simulated (a) SHF and (b) LHF with the COARE simulation.

Figure 7a shows that almost $50 \%$ shortwave solar radiation is absorbed by the mixed layer. In AOSIS, this process warms the mixed layer and is equivalent to the so-called warm-layer effect in COARE. Since $T_{0}$ is larger than $T_{a}$ (Fig. 7c), heat is released into the atmosphere through longwave radiation $R_{n}$, latent heat flux $H_{1}$ and sensible heat flux $H_{s}$. This process cools the ocean surface and is equivalent to the so-called cool-skin effect of COARE.

As Fig. 7c shows, AOSIS correctly predicts the daily cycle of SST: high in the afternoon and low at night. But the average SST of COARE is higher than that of AOSIS. As shown by Table 5, the average AOSIS SST over the simulating period is $302.18 \mathrm{~K}$, which is $0.1 \mathrm{~K}$ lower than the average COARE SST $(302.28 \mathrm{~K})$. The fractional bias between AOSIS SST and COARE SST is nearly zero. This means AOSIS can simulate the long-term mean SST quiet well. The degree of agreement between AOSIS SST and COARE SST is 0.86 ; correlation coefficient is 0.82 . This shows that the AOSIS simulation is in good agreement with the COARE simulation. From Fig. 7d, we can see that $\operatorname{AOSIS~SST~}\left(T_{0}\right)$ is cooler than the bulk temperature of the mixed layer $T_{1}$ by about $0.1-0.4 \mathrm{~K}$ after the sea surface reaches the peak SST in the late afternoon and at night. The average $T_{0}$ is cooler than $T_{1}$ by $0.1 \mathrm{~K}$.
Figure 8 shows the sensible heat flux and latent heat flux computed from AOSIS in comparison with the COARE simulation. The sensible heat flux computed from AOSIS is in good agreement with the COARE simulation. The AOSIS sensible heat flux has a mean of $6.78 \mathrm{~W} \mathrm{~m}^{-2}, 0.15 \mathrm{~W} \mathrm{~m}^{-2}$ lower than the COARE mean $\left(6.93 \mathrm{~W} \mathrm{~m}^{-2}\right)$. The fractional bias is low, only 0.02 . The degree of agreement and the correction coefficient are both high, 0.96 and 0.92 , respectively. The AOSIS latent heat flux is also in good agreement with the COARE simulation. Its mean value is $93.71 \mathrm{~W} \mathrm{~m}^{-2}, 6.54 \mathrm{~W} \mathrm{~m}^{-2}$ higher than that of COARE mean $\left(87.17 \mathrm{~W} \mathrm{~m}^{-2}\right)$. The fractional bias is 0.07 . The degree of agreement and the correction coefficient are both high, 0.87 and 0.78 , respectively.

\section{3) NCEP: RESULTS AND DISCUSSION}

Although this study is focused on subseasonal time scales, we try to test the ability of AOSIS to do seasonal simulation. To verify AOSIS against NCEP data for 1-yr period, four datasets from different locations and different time periods are used. Two locations at the open sea and the other two at the coastal sea are chosen to compare the simulation skills of AOSIS at open and coastal seas. Since we will apply AOSIS to study Australian 
TABLE 6. Year, location, and sea state of the four NCEP datasets for AOSIS verification.

\begin{tabular}{|c|c|c|c|c|c|}
\hline Case & Year & Location & Longitude & Latitude & Sea state \\
\hline A & 1990 & Southeast Pacific Ocean & $270^{\circ} \mathrm{E}$ & $20^{\circ} \mathrm{S}$ & Open sea \\
\hline $\mathrm{B}$ & 2000 & Near Darwin & $127.5^{\circ} \mathrm{E}$ & $12.5^{\circ} \mathrm{S}$ & Coastal sea \\
\hline $\mathrm{C}$ & 2002 & North Pacific Ocean & $170.5^{\circ} \mathrm{E}$ & $29.5^{\circ} \mathrm{N}$ & Open sea \\
\hline $\mathrm{D}$ & 2003 & Near Sydney & $152.5^{\circ} \mathrm{E}$ & $32.5^{\circ} \mathrm{S}$ & Coastal sea \\
\hline
\end{tabular}

monsoon in the future, the coastal seas near Darwin, Australia (north), and Sydney, Australia (south), are chosen. In the open-sea cases, one is at the Southern Hemisphere and the other is at the Northern Hemisphere. Details of the datasets are listed in Table 6. The statistical analysis results of the four cases are shown in Table 7.

As shown in Table 7, the statistical analysis of simulation results for all four cases is in high agreement with the NCEP data. Figure 9 shows that AOSIS successfully simulates the annual SST patterns. The average SST degree of agreement and correlation coefficient are both high, 0.90 and 0.85 , respectively. The differences between mean AOSIS SST and mean NCEP SST for cases A, B, C, and D are 0.02, $0.06,0.02$, and $0.06 \mathrm{~K}$, respectively. AOSIS calculates SST more correctly in open-sea area (cases A and C) than in the coastal sea area (cases B and D). Of the open-sea cases, the SST degrees of agreement and the SST correlation coefficients are higher, the differences between the means of NCEP SST and AOSIS SST are smaller, the mean $K_{\mathrm{hw}}$ is higher, the minimum $h_{1}$ is smaller, and the differences between the mean sensible and latent heat flux of NCEP and AOSIS are smaller. Of the four cases, the simulation result of case $\mathrm{C}$ is the best. The simulation result of case $\mathrm{D}$ is not quite in agreement with NCEP. Its annual change is faster than that of NCEP. Since AOSIS is a one-dimension model and does not consider the influence of ocean currents, it inevitably has inaccuracies if time step values are considered. The errors will be larger if they are accumulated over a long time period and may increase to about $4 \mathrm{~K}$.

Figures 10 and 11 show the scatterplots of sensible and latent heat flux from AOSIS and NCEP for the cases (Table 6). In general, the results of AOSIS are in agreement with the NCEP data. Among the four cases, cases A and $\mathrm{C}$ (open seas) have better performance than cases $\mathrm{B}$ and $\mathrm{D}$ (coastal seas). This is because AOSIS has not considered the influence of the complex dynamic factors in the coastal sea, such as narrower water and fetch, etc.

\section{e. Summary}

We have tested AOSIS in stand-alone mode against the Moana Wave data and the NCEP data. This is done in two steps:

1) The wind-wave scheme of AOSIS is tested without the SST scheme in offline point mode against the
Moana Wave data. It was found that AOSIS performs better in simulating the wave age, total momentum stress, and wave-induced stress than the wind-wave schemes proposed by Taylor and Yelland (2001) and Oost et al. (2002). The AOSIS simulations of roughness Reynolds number $R_{r}$ scalar transfer coefficient $C_{e}$, drag transfer coefficient $\mathrm{C}_{d}$, aerodynamic roughness length $z_{0 \mathrm{~m}}$, and energy fluxes are in good agreement with the COARE estimates.

2) AOSIS is then tested with the SST scheme in offline point mode against the Moana Wave data and the NCEP data. The comparison with the Moana Wave data shows that AOSIS has considerable skill in simulating SST and energy fluxes, with the simulated values in good agreement with observation data. AOSIS is also successful in simulating the warm-layer and cool-skin effects considered in the COARE scheme. Comparison with the NCEP data also confirms that AOSIS simulates SST and surface energy fluxes well.

\section{Conclusions}

The focus of this study is on the parameterization of atmosphere-ocean surface interaction. A new atmosphereocean surface interaction scheme, referred to as AOSIS, has been developed and verified with observed data.

TABLE 7. Statistical analysis of the four NCEP cases.

\begin{tabular}{|c|c|c|c|c|}
\hline Case & A & B & $\mathrm{C}$ & $\mathrm{D}$ \\
\hline Mean NCEP SST (K) & 294.59 & 301.90 & 296.65 & 292.74 \\
\hline Mean AOSIS SST (K) & 294.61 & 301.84 & 296.63 & 292.88 \\
\hline Mean AOSIS $T_{1}(\mathrm{~K})$ & 294.67 & 301.96 & 296.70 & 292.99 \\
\hline Mean AOSIS $T^{*}(\mathrm{~K})$ & 292.98 & 299.66 & 294.61 & 291.52 \\
\hline SST degree of agreement & 0.92 & 0.87 & 0.95 & 0.86 \\
\hline SST correlation coef & 0.86 & 0.81 & 0.91 & 0.81 \\
\hline Mean $K_{\mathrm{hw}}\left(10^{-3} \mathrm{~m}^{2} \mathrm{~s}^{-1}\right)$ & 7.0 & 5.7 & 7.1 & 6.4 \\
\hline Minimum $h_{1}(\mathrm{~m})$ & 0.45 & 2.2 & 1.3 & 2.0 \\
\hline $\begin{array}{l}\text { Mean depth of } \\
\text { thermocline }(\mathrm{m})\end{array}$ & 52.5 & 53.5 & 48.9 & 58.9 \\
\hline $\begin{array}{l}\text { Mean NCEP } \\
\text { SHF }\left(\mathrm{W} \mathrm{m}^{-2}\right)\end{array}$ & 15.12 & 11.67 & 14.61 & 35.45 \\
\hline $\begin{array}{l}\text { Mean AOSIS } \\
\text { SHF }\left(\mathrm{W} \mathrm{m}^{-2}\right)\end{array}$ & 18.11 & 11.52 & 14.17 & 30.76 \\
\hline $\begin{array}{l}\text { Mean NCEP } \\
\text { LHF }\left(\mathrm{W} \mathrm{m}^{-2}\right)\end{array}$ & 115.28 & 155.88 & 126.20 & 142.94 \\
\hline $\begin{array}{l}\text { Mean AOSIS } \\
\quad \text { LHF }\left(\mathrm{W} \mathrm{m}^{-2}\right)\end{array}$ & 113.07 & 159.68 & 123.30 & 117.36 \\
\hline
\end{tabular}



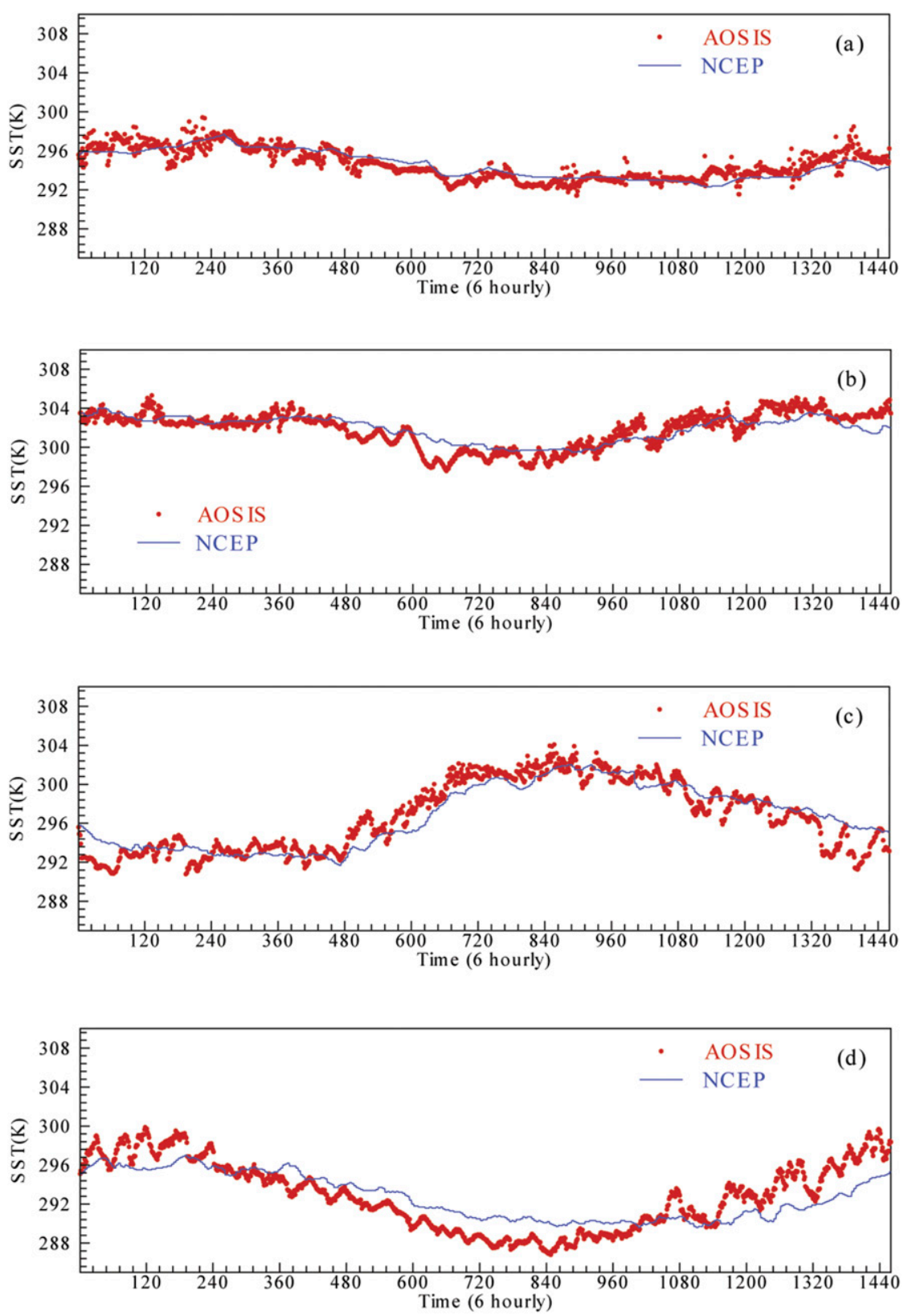

FIG. 9. SST computed from AOSIS with four NCEP datasets (Table 6).

Adequate parameterizations of atmosphere-ocean surface interaction are important to quantify the exchanges of energy, mass, and momentum at the atmosphereocean interfaces. They are also important to quantify surface quantities, such as SST, which are key factors to atmospheric circulations on a wide range of time scales.

The ocean surface is mobile and semitransparent to solar radiation. As a consequence, the aerodynamic characteristic of the ocean surface (as reflected in roughness length) is wind velocity dependent because of windgenerated waves and the characteristics of ocean surface energy balance. Based on this understanding, AOSIS is constructed with three basic components: a two-layer ocean temperature model, a wind-wave model, and a surface flux model.

The capacity of an ocean temperature scheme for the prediction of SST is of great importance. To our best knowledge, in most regional atmospheric prediction models, weekly or even monthly SST data are used. 
(a)

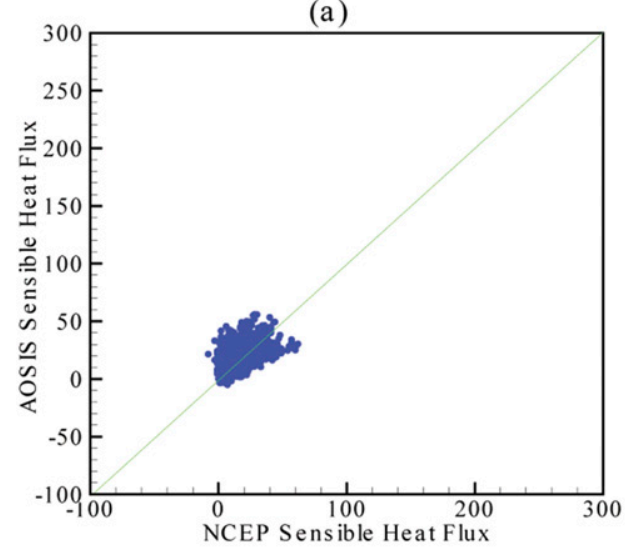

(c)

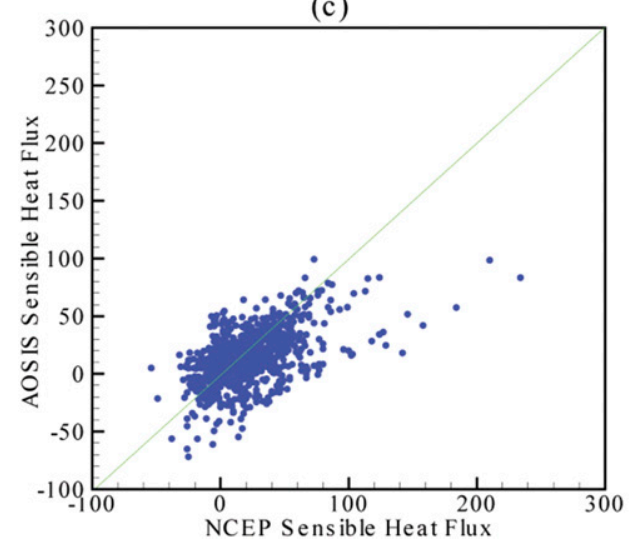

(b)

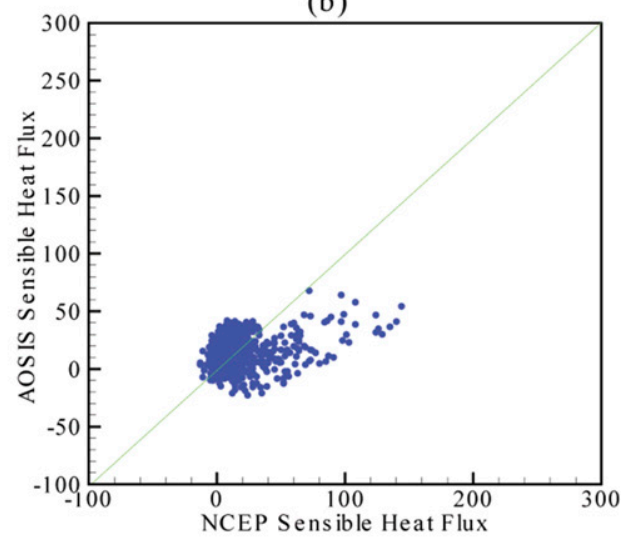

(d)

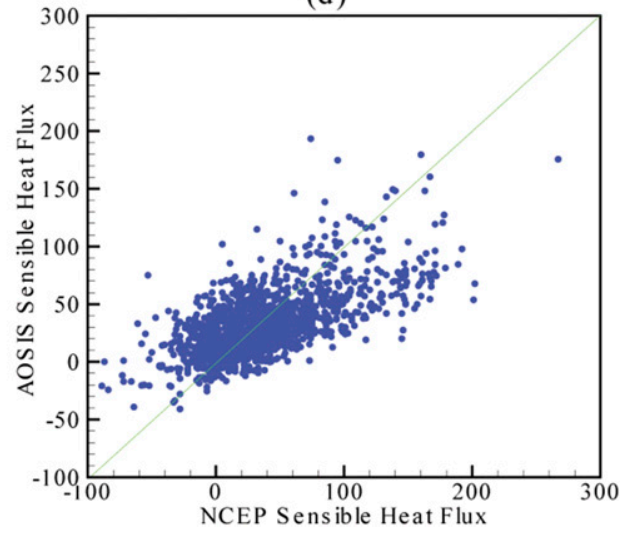

FIG. 10. Scatterplots of SHF from AOSIS and NCEP with four NCEP datasets (Table 6).

This is unsatisfactory, as SST does show clear diurnal variations, which considerably affect the energy exchanges at the atmosphere-ocean interface. Thus, advanced ocean temperature schemes must be able to simulate such diurnal variations. Another reason for placing emphasis on SST is that in experimental studies, SST is difficult to measure directly, and a model is often required to derive SST from other readily measurable atmospheric and oceanic quantities.

The justification for the two-layer ocean temperature model is as follows: ocean temperature and salinity are usually well mixed in a shallow layer below the sea surface known as the mixed layer. This layer has a near-neutral stratification. The mixed layer tends to be bounded below by stratified pycnoclines. Within the mixed layer, the vertically uniform distributions of conservative properties are maintained by wind-generated large eddies. The evolution of the mixed layer temperature is determined primarily by solar radiation and the energy fluxes at the upper and lower boundaries of the mixed layer. The changes arising from horizontal advection due to ocean currents are negligible on the time scales concerned in this study. Based on this argument, we divide the ocean into a mixed layer and a deep layer. However, we emphasize the depth of the mixed layer is not constant but varies with time, depending on surface wind stress and buoyancy flux.

Both eddy and molecular diffusivities affect transport processes in ocean. For the deep ocean layer, molecular diffusivity $\kappa_{m}$ dominates. In the mixed layer, eddy diffusivity $K_{\mathrm{hw}}$ dominates; $K_{\mathrm{hw}}$ is allowed to vary with sea state and stability. It is set to be proportioned to $U_{* w}$. Since the molecular diffusivity is generally much smaller than the eddy diffusivities, its effect on the heat flux can be ignore in the mixed layer.

In AOSIS, the Monin-Obukhov similarity functions for the atmospheric boundary layer over the ocean surface are specified according to Fairall et al. (1996b). They give good agreement with the Businger-Dyer formulation for near-neutral stratifications and at the same time satisfy the free-convection limit.

In windy conditions, sea surface is full of waves resulting in varying aerodynamic roughness lengths in 
(a)

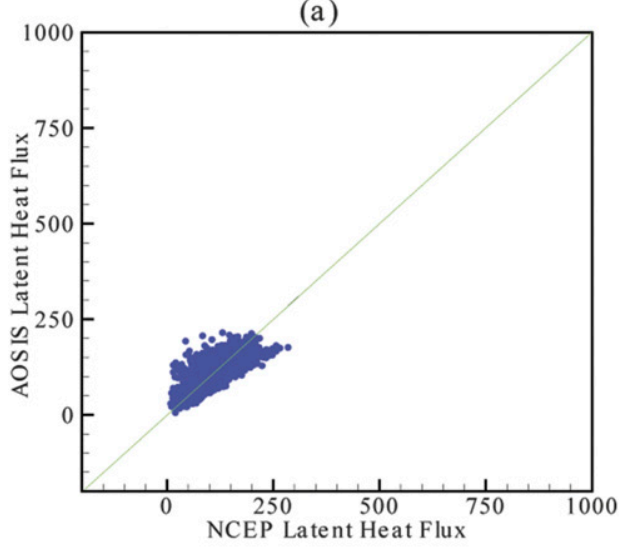

(c)

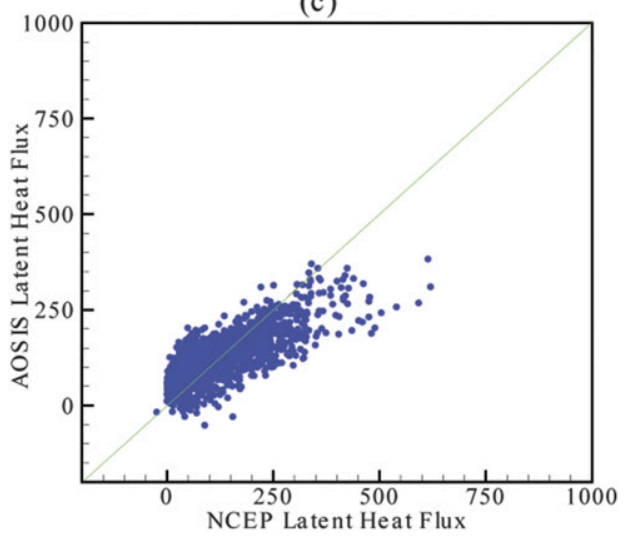

(b)

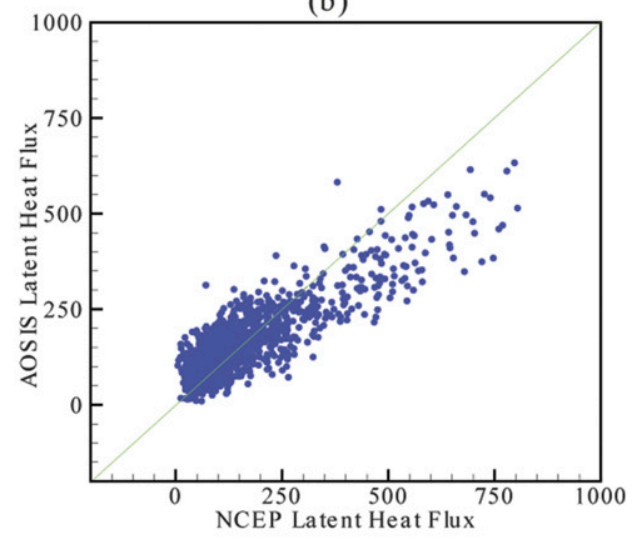

(d)

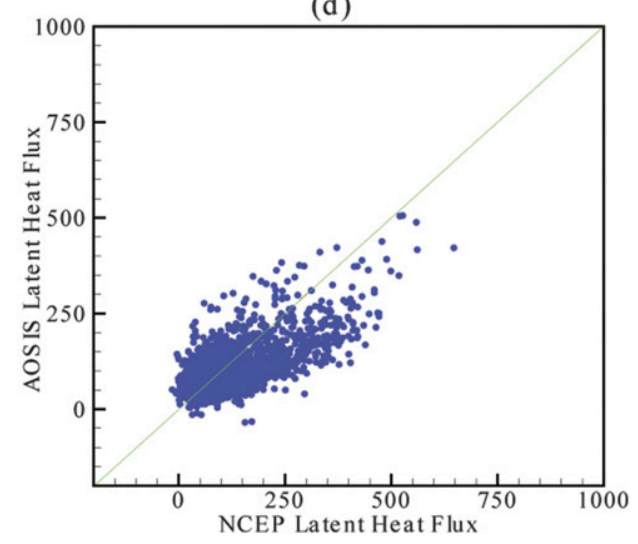

FIG. 11. As in Fig. 10, but for latent heat flux.

space and time. In turn, wind profile is affected by surface waves; hence, the growth of waves also depends on the sea state. Thus, the wind profile must be different from that over a flat plate. In AOSIS, we have adapted the approach to relate the stages of wave development by wave age. Snyder et al. (1981) found that the momentum transfer from wind to waves is considerable so that the related wave-induced stress is a substantial fraction of the total stress in the surface layer. This suggests that the drag and other bulk transfer coefficient must depend on the sea state. A widely used empirical expression for sea surface roughness length $z_{0 \mathrm{~m}}$ is the Charnock (1955) model. Recent research suggested that $z_{0 \mathrm{~m}}$ should be related to wave age and wave slope. In this study, we proposed a new expression for calculating $z_{0 \mathrm{~m}}$ that considers waves.

We have tested AOSIS in a stand-alone mode against the Moana Wave data and the NCEP data. This is done in two steps:

1) The wind-wave scheme of AOSIS is tested without the SST scheme against the Moana Wave data. It has been found that AOSIS performs better in simulating the wave age, total momentum stress, and waveinduced stress than the wind-wave schemes proposed by Taylor and Yelland (2001) and Oost et al. (2002). The AOSIS simulations of roughness Reynolds number $R_{r}$, heat and moisture bulk transfer coefficients $C_{h}$ and $C_{e}$, drag transfer coefficient $C_{d}$, aerodynamic roughness length $z_{0 \mathrm{~m}}$, and energy fluxes are in good agreement with the COARE estimates.

2) AOSIS is then tested with the SST scheme against the Moana Wave data and the NCEP data. The comparison with the Moana Wave data shows that AOSIS has considerable skill in simulating SST and energy fluxes, with the simulated values in good agreement with the observation data. AOSIS is also successful in simulating the warm-layer and cool-skin effects considered in the COARE scheme. Comparison with the NCEP data also confirms that AOSIS simulates SST well.

The numerical experiments show that AOSIS has considerable skill in representing ocean surface processes. AOSIS SST has been found to agree well with 
the NCEP SST in daily averages, and AOSIS has the advantage in that it can also simulate the diurnal variations of SST, which has been found to be around $1 \mathrm{~K}$, sufficiently significant in producing considerable variations in surface energy fluxes. The AOSISpredicted latent heat flux and sensible heat flux have also been found to agree well with the corresponding NCEP data.

In summary, this study is a contribution to the parameterization of atmosphere-ocean interaction, especially to the prediction of SST daily anomalies and the simulation of ocean surface roughness length, taking into account the wind-wave effect. The two-layer ocean temperature model simulates SST and the cool-skin and warm-layer effect of the ocean mixed layer without the input of ocean bulk temperature observation data, which is required by most one-layer models (e.g., Fairall et al. 1996a,b). It not only considers the heat transport inside the mixed layer but also the sublayer between the mixed layer and the thermocline. The wind-wave model simulates better ocean surface roughness length with a new algorithm by taking into account wind-induced stress. The newly developed AOSIS performs well in simulating the atmosphere-ocean exchanges; it not only provides a better lower-boundary condition for atmospheric modeling but also serves as a modeling tool for SST calculation using observed data.

The horizontal energy transport in the mixed layer caused by ocean current and turbulence is ignored in this study because the time scale of concern in this study is subseasonal. For seasonal and interannual climate research, the horizontal contributors to the heat budget in the ocean mixed layer are important and hence cannot be ignored. Several recent studies quantified the oceanic processes contributing to SST variability in the tropical Pacific Ocean on seasonal and interannual time scales. (Enfield et al. 1986) and Hayes et al. (1991) highlighted that meridional advection induced by the equatorial divergence was also contributing to the eastern Pacific SST budget. Wang and McPhaden (2000) found that both atmospheric forcing and cooling by zonal advection are important in the seasonal cycle of SST in the western Pacific. On the interannual time scales, zonal advection becomes the predominant effect.

In future studies, AOSIS will be coupled with an ocean model to better account for the detailed ocean dynamic and thermal processes.

Acknowledgments. Support for this research was provided by the Scientific Research Foundation of the State Human Resource Ministry and the Education Ministry for Returned Chinese Scholars, China; the Young Program of Application Basic and Cutting-Edge Technologies Research Plan, Tianjin, China, under Contract 15JCQNJC07600; and Research on Key Techniques of Numerical Prediction of Sea Fog Disaster in Tianjin Coastal Area, under Contract KJXH2014-20.

\section{REFERENCES}

Anderson, S. P., R. A. Weller, and R. B. Lukas, 1996: Surface buoyancy forcing and the mixed layer of the western Pacific warm pool: Observations and 1D model results. J. Climate, 9, 3056-3085, https://doi.org/10.1175/15200442(1996)009<3056:SBFATM > 2.0.CO;2.

Businger, J. A., 1966: Transfer of momentum and heat in the atmospheric boundary layer. Proc. Arctic Heat Budget and Atmospheric Circulation, Santa Monica, CA, RAND Corporation, 305-332.

Chan, J. C. L., Y. Duan, and L. K. Shay, 2001: Tropical cyclone intensity change from a simple ocean-atmosphere coupled model. J. Atmos. Sci., 58, 154-172, https://doi.org/10.1175/ 1520-0469(2001)058<0154:TCICFA > 2.0.CO;2.

Charnock, H., 1955: Wind stress on a water surface. Quart. J. Roy. Meteor. Soc., 81, 639-640, https://doi.org/10.1002/ qj.49708135027.

Donelan, M. A., F. W. Dobson, S. D. Smith, and R. J. Anderson, 1993: On the dependence of sea surface roughness on wave development. J. Phys. Oceanogr., 23, 2143-2149, https://doi. org/10.1175/1520-0485(1993)023<2143:OTDOSS > 2.0.CO;2.

Drennan, W. M., H. C. Graber, D. Hauser, and C. Quentin, 2003: On the wave age dependence of wind stress over pure wind seas. J. Geophys. Res., 108, 8062, https://doi.org/10.1029/2000JC000715.

Dyer, A. J., 1974: A review of flux-profile relationships. Bound.-Layer Meteor., 7, 363-372, https://doi.org/10.1007/BF00240838.

Enfield, D. B., 1986: Zonal and seasonal variations in the near surface heat balance of the equatorial ocean. J. Phys. Oceanogr., 16, 1038-1054, https://doi.org/10.1175/1520-0485(1986)016<1038: ZASVOT $>2.0 . \mathrm{CO} ; 2$.

Fairall, C. W., E. F. Bradley, J. S. Godfrey, G. A. Wick, J. B. Edson, and G. S. Young, 1996a: Cool-skin and warm-layer effects on sea surface temperature. J. Geophys. Res., 101, 1295-1308, https://doi.org/10.1029/95JC03190.

$\longrightarrow,-$ D. P. Rogers, J. B. Edson, and G. S. Young, 1996b: Bulk parameterization of air-sea fluxes for Tropical Ocean-Global Atmosphere Coupled-Ocean Atmosphere Response Experiment. J. Geophys. Res., 101, 3747-3764, https://doi.org/ 10.1029/95JC03205.

,-- J. E. Hare, A. A. Grachev, and J. B. Edson, 2003: Bulk parameterization of air-sea fluxes: Updates and verification for the COARE algorithm. J. Climate, 16, 571-591, https:/ doi.org/10.1175/1520-0442(2003)016<0571:BPOASF >2.0.CO;2.

Garratt, J. R., 1977: Review of drag coefficients over oceans and continents. Mon. Wea. Rev., 105, 915-929, https://doi.org/ 10.1175/1520-0493(1977)105<0915:RODCOO>2.0.CO;2.

_ 1992: The Atmospheric Boundary Layer. Cambridge University Press, $334 \mathrm{pp}$.

Godfrey, J. S., and A. C. M. Beljaars, 1991: On the turbulent fluxes of buoyancy, heat, and moisture at the air-sea interface at low wind speeds. J. Geophys. Res., 96, 22 043-22 048, https:// doi.org/10.1029/91JC02015.

Grachev, A. A., C. W. Fairall, and E. F. Bradley, 2000: Convective profile constants revisited. Bound.-Layer Meteor., 94, 495-515, https://doi.org/10.1023/A:1002452529672.

Hayes, S., P. Chang, and M. McPhaden, 1991: Variability of the sea surface temperature in the eastern equatorial Pacific during 1986-88. J. Geophys. Res., 96, $10553-10566$, https://doi.org/ 10.1029/91JC00942. 
Hsu, S. A., 1974: A dynamic roughness equation and its application to wind stress determination at the air-sea interface. J. Phys. Oceanogr., 4, 116-120, https://doi.org/10.1175/15200485(1974)004<0116:ADREAI>2.0.CO;2.

Janssen, P. A. E. M., 1982: Quasilinear approximation for the spectrum of wind-generated water waves. J. Fluid Mech., 117, 493-506, https://doi.org/10.1017/S0022112082001736.

__ 1991: Quasi-linear theory of wind-wave generation applied to wave forecasting. J. Phys. Oceanogr., 21, 1631-1642, https://doi.org/ 10.1175/1520-0485(1991)021<1631:QLTOWW>2.0.CO;2.

— , G. J. Komen, and W. J. P. de Voogt, 1984: An operational coupled hybrid wave prediction model. J. Geophys. Res., 89, 3635-3654, https://doi.org/10.1029/JC089iC03p03635.

Jeffreys, H., 1925: On the formation of waves by wind. Proc. Roy. Soc. London, 107A, 189-206, https://doi.org/10.1098/rspa.1925.0015.

— 1926: On the formation of waves by wind (second paper). Proc. Roy. Soc. London, 110A, 241-247, https://doi.org/ 10.1098/rspa.1926.0014.

Johnson, H. K., J. Højstrup, H. J. Vested, and S. E. Larsen, 1998: Dependence of sea surface roughness on wind waves. J. Phys. Oceanogr., 28, 1702-1716, https://doi.org/10.1175/1520-0485 (1998)028<1702:OTDOSS > 2.0.CO;2.

Kalnay, E., and Coauthors, 1996: The NCEP/NCAR 40-Year Reanalysis Project. Bull. Amer. Meteor. Soc., 77, 437-471, https:// doi.org/10.1175/1520-0477(1996)077<0437:TNYRP>2.0.CO;2.

Komen, G. J., L. Cavaleri, M. Donelan, K. Hasselmann, S. Hasselmann, and P. A. E. M. Janssen, 1996: Dynamics and Modelling of Ocean Waves. Cambridge University Press, 556 pp.

Kraus, E. B., and J. A. Businger, 1994: The planetary boundary layer. Atmosphere-Ocean Interaction, Oxford University Press, 182-235.

Large, W. G., J. C. McWilliams, and S. C. Doney, 1994: Oceanic vertical mixing: A review and a model with a nonlocal boundary layer parameterization. Rev. Geophys., 32, 363-403, https://doi.org/10.1029/94RG01872.

Liu, W. T., K. B. Katsaros, and J. A. Businger, 1979: Bulk parameterization of the air-sea exchange of heat and water vapor including the molecular constraints at the interface. J. Atmos. Sci., 36, 1722-1735, https://doi.org/10.1175/15200469(1979)036<1722:BPOASE > 2.0.CO;2.

Lukas, R., and P. Webster, 1992: TOGA-COARE, Tropical Ocean Global Atmosphere Program and Coupled OceanAtmosphere Response Experiment. Oceanus, 35, 62-65.

Miles, J. W., 1957: On the generation of surface waves by shear flows. J. Fluid Mech., 3, 185-204, https://doi.org/10.1017/ S0022112057000567.

Nikuradse, J., 1933: Strömungsgesetze in rauhen Rohren. Forschungsheft auf dem Gebiete des Ingenieurwesens, Vol. 361, VDI, $22 \mathrm{pp}$.

Oost, W. A., G. J. Komen, C. M. J. Jacobs, and C. Van Oort, 2002: New evidence for a relation between wind stress and wave age from measurements during ASGAMAGE. Bound.-Layer Meteor., 103, 409-438, https://doi.org/10.1023/A:1014913624535.

Panofsky, H. A., and J. A. Dutton, 1984: Atmospheric Turbulence: Models and Methods for Engineering Applications. WileyInterscience, $397 \mathrm{pp}$.

Phillips, O. M., 1957: On the generation of waves by turbulent wind. J. Fluid Mech., 2, 417-445, https://doi.org/10.1017/ S0022112057000233.

Price, J. F., R. A. Weller, and R. Pinkel, 1986: Diurnal cycling: Observations and models of the upper ocean response to diurnal heating, cooling, and wind mixing.
J. Geophys. Res., 91, 8411-8427, https://doi.org/10.1029/ JC091iC07p08411.

Saunders, P. M., 1967: The temperature at the ocean-air interface. J. Atmos. Sci., 24, 269-273, https://doi.org/10.1175/15200469(1967)024<0269:TTATOA > 2.0.CO;2.

Schumann, U., 1988: Minimum friction velocity and heat transfer in the rough surface layer of a convective boundary layer. Bound.Layer Meteor., 44, 311-326, https://doi.org/10.1007/BF00123019.

Smith, S. D., 1981: Comment [on "A new evaluation of the wind stress coefficient over water surfaces"]. J. Geophys. Res., 86, 4307-4307, https://doi.org/10.1029/JC086iC05p04307.

_ 1988: Coefficients for sea surface wind stress, heat flux, and wind profiles as a function of wind speed and temperature. J. Geophys. Res., 93, 15 467-15 472, https://doi.org/10.1029/ JC093iC12p15467.

1989: Water vapor flux at the sea surface. Bound.-Layer Meteor., 47, 277-293, https://doi.org/10.1007/BF00122334.

_ efficients: The HEXOS results. Bound.-Layer Meteor., 60, 109-142, https://doi.org/10.1007/BF00122064.

, C. W. Fairall, G. L. Geernaert, and L. Hasse, 1996: Air-sea fluxes: 25 years of progress. Bound.-Layer Meteor., 78, 247290, https://doi.org/10.1007/BF00120938.

Snyder, R. L., F. W. Dobson, J. A. Elliot, and R. B. Long, 1981: Array measurements of atmospheric pressure fluctuations above surface gravity waves. J. Fluid Mech., 102, 1-59, https:// doi.org/10.1017/S0022112081002528.

Soloviev, A. V., 1982: On vertical structure of the thin surface layer of the ocean at weak winds. Fiz. Atmos. Okeana, 18, 579-585.

Sui, C.-H., X. Li, K.-M. Lau, and D. Adamec, 1997: Multiscale air-sea interactions during TOGA COARE. Mon. Wea. Rev., 125, 448-462, https://doi.org/10.1175/1520-0493(1997)125<0448: MASIDT>2.0.CO;2.

Sverdrup, H. U., M. W. Johnson, and R. H. Fleming, 1942: The Oceans: Their Physics, Chemistry, and General Biology. Prentice-Hall, 1087 pp.

Taylor, P. K., and M. J. Yelland, 2001: The dependence of sea surface roughness on the height and steepness of the waves. J. Phys. Oceanogr., 31, 572-590, https://doi.org/10.1175/15200485(2001)031<0572:TDOSSR > 2.0.CO;2.

Wang, W., and M. J. McPhaden, 2000: The surface-layer heat balance in the equatorial Pacific Ocean. Part II: Interannual variability. J. Phys. Oceanogr., 30, 2989-3008, https://doi.org/ 10.1175/1520-0485(2001)031<2989:TSLHBI>2.0.CO;2.

Wu, J., 1980: Wind stress coefficients over the sea surface near neutral conditions-A revisit. J. Phys. Oceanogr., 10, 727-740, https:// doi.org/10.1175/1520-0485(1980)010<0727:WSCOSS >2.0.CO;2.

Wu, X., and M. W. Moncrieff, 2001: Long-term behavior of cloud systems in TOGA COARE and their interactions with radiative and surface processes. Part III: Effects on the energy budget and SST. J. Atmos. Sci., 58, 1155-1168, https://doi.org/ 10.1175/1520-0469(2001)058<1155:LTBOCS $>2.0$. CO;2.

Yelland, M. J., B. I. Moat, P. K. Taylor, R. W. Pascal, J. Hutchings, and V. C. Cornell, 1998: Wind stress measurements from the open ocean corrected for airflow distortion by the ship. J. Phys. Oceanogr., 28, 1511-1526, https://doi.org/10.1175/ 1520-0485(1998)028<1511:WSMFTO > 2.0.CO;2.

Zeng, X., M. Zhao, R. E. Dickinson, and Y. He, 1999: A multiyear hourly sea surface skin temperature data set derived from the TOGA TAO bulk temperature and wind speed over the tropical Pacific. J. Geophys. Res., 104, 1525-1536, https:// doi.org/10.1029/1998JC900060. 